\title{
Immune-based therapies for hepatocellular carcinoma
}

\author{
David J. Pinato $\mathbb{D}^{1} \cdot$ Nadia Guerra ${ }^{2} \cdot$ Petros Fessas $^{1} \cdot$ Ravindhi Murphy $^{1} \cdot$ Takashi Mineo $^{3} \cdot$ Francesco A. Mauri $^{1}$. \\ Sujit K. Mukherjee ${ }^{4} \cdot$ Mark Thursz $^{4} \cdot$ Ching Ngar Wong $^{1} \cdot$ Rohini Sharma $^{1} \cdot$ Lorenza Rimassa $^{5,6}$
}

Received: 16 September 2019 / Revised: 19 February 2020 / Accepted: 25 February 2020 / Published online: 10 March 2020

(c) The Author(s) 2020. This article is published with open access

\begin{abstract}
Hepatocellular carcinoma (HCC) is the third most frequent cause of cancer-related death. The immune-rich contexture of the HCC microenvironment makes this tumour an appealing target for immune-based therapies. Here, we discuss how the functional characteristics of the liver microenvironment can potentially be harnessed for the treatment of HCC. We will review the evidence supporting a therapeutic role for vaccines, cell-based therapies and immune-checkpoint inhibitors and discuss the potential for patient stratification in an attempt to overcome the series of failures that has characterised drug development in this disease area.
\end{abstract}

\section{Introduction}

Hepatocellular carcinoma (HCC) is a prototypical inflammation-driven cancer arising on the backdrop of liver cirrhosis. Whilst the epidemiology of chronic liver disease is changing from a largely hepatitis virus $\mathrm{B}(\mathrm{HBV})$ or $\mathrm{C}$ (HCV) driven landscape to a predominantly metabolic one, with non-alcoholic steato-hepatitis (NASH) rapidly increasing in prevalence [1], tumour-promoting inflammation remains the common denominator that characterises the pathogenesis of HCC across aetiologies.

The high lethality of HCC, a cancer of increasing incidence [2], stems from late-stage presentation and high prevalence of concomitant liver dysfunction [3]. Curative

David J. Pinato

david.pinato@imperial.ac.uk

1 Department of Surgery \& Cancer, Imperial College London, Hammersmith Hospital, Du Cane Road, London W120HS, UK

2 Department of Life Sciences, Imperial College London, South Kensington Campus, Exhibition Road, London SW7 2AZ, UK

3 Tokyo Medical and Dental University, Tokyo, Japan

4 Department of Metabolism, Digestion \& Reproduction, Imperial College London, St. Mary's Hospital, Praed Street, London, UK

5 Medical Oncology and Haematology Unit, Humanitas Cancer Center, Humanitas Clinical and Research Center-IRCCS, Via Manzoni 56, 20089 Rozzano, Milan, Italy

6 Department of Biomedical Sciences, Humanitas University, Via Rita Levi Montalcini, 20090 Pieve Emanuele, Milan, Italy approaches (liver resection, ablation) in early-stage HCC are affected by high recurrence rates [4] and transplantation is feasible only within rigorous oncological criteria [5]. As cancer and liver dysfunction progress, loco-regional and systemic therapy may improve patients' survival. Whilst significant survival benefit is now achievable with optimal treatment sequencing [6], all patients within Barcelona Clinic Liver Cancer intermediate and advanced stages will inevitably die of HCC.

After decades of failures and scepticism over the potential for immune-based therapies to produce clinically meaningful disease-modulating effects, the systemic management of cancer has been recently revolutionised by the advent of immune checkpoint inhibitors (ICPI), a therapeutic class of monoclonal antibodies that can effectively induce tumour immune-rejection by targeting key coinhibitory signals within the cancer-immunity interface. Over the past decade, anti-cancer immunotherapy with inhibitors of the programmed cell-death 1 receptor or ligand 1 (PD-1/PD-L1) and Cytotoxic T-cell antigen 4 (CTLA-4) has swiftly become standard of care across a wide range of previously untreatable malignancies including non-small cell lung cancer (NSCLC), melanoma and many others. The strong immune-mediated pathogenesis of HCC makes this tumour particularly appealing for immune-based therapies. However, the complex functional characteristics of the HCC tumour microenvironment (TME) highlight the presence of multiple non-redundant mechanisms of cancer immune-suppression, which synergise in defining a high barrier of resistance to immunotherapy. By the time HCC is diagnosed, the various functional segments of the host's 
immunity are strongly geared towards immune-suppression by un-resolved pro-inflammatory stimuli that accompany liver fibrogenesis through a process now recognised as immuno-editing [7].

In the specific context of $\mathrm{HCC}$, anti-tumour immune reconstitution with ICPIs has produced initial enthusiasm based on preliminary results from single-arm studies [8, 9], suggesting evidence of anti-tumour activity. With immunotherapy rapidly expanding as a novel option in the treatment landscape of HCC [10], we discuss the rationale for the development of immune-based therapies in liver cancer and review the basic immune-biologic mechanism that underlie the progression of HCC and might be exploited for therapy.

\section{Molecular mechanisms of hepatic immune tolerogenesis}

Sitting at the functional junction between portal and arterial inflow, the liver constitutes a primary anatomical site of immune recognition, facilitated by the low pressure, low flow sinusoidal architecture capable of exposing potential pathogens to the largest reticulo-endothelial system present in the human body [11].

To protect the liver parenchyma from unopposed tissue injury, several mechanisms contribute to naturally prevent unwanted immune responses generated from exposure to microbial antigens and conserved molecular motifs known as danger- or pathogen-associated molecular patterns (DAMPs/ PAMPs), making the liver a largely immune-suppressive microenvironment. The functional heterogeneity of the liver immune microenvironment is evidenced by the multifaceted nature of stromal cells including liver sinusoidal endothelial cells (LSECs), hepatic stellate cells (HSCs), liver resident macrophages or Kupffer cells (KCs) as well as numerous functional segments of the adaptive immune response including CD4+, CD8+ T-lymphocytes and NK cells [12].

LSECs are endowed with antigen-presenting capacity, being able to activate antigen specific CD4+ T-cell responses [13]. LSECs modulate immune cell recruitment through specific integrins $(\alpha \mathrm{L} \beta 2, \alpha 4 \beta 1, \alpha 4 \beta 7)$ that facilitate capture, firm lymphocyte adhesion and subsequent chemotaxis mediated by pathways such as CXCL9-11/CXCR3,

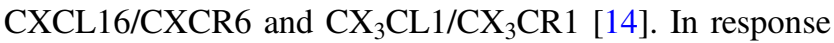
to lipopolysaccharide (LPS), the prototypical PAMP molecule, the antigen-presentation capacity of LSECs is dampened by downregulation of constitutively expressed Major Histocompatibility Complex (MHC) class II, CD80 and CD86 molecules [15]. Key driver of this immunetolerogenic state is the relative abundance of prostaglandin E2 (PGE2) and interleukin 10 (IL-10), two immune-suppressive mediators produced by KC and LSECs in response to chronic LPS exposure.
Transforming growth factor- $\beta$ (TGF- $\beta$ ), another key immunosuppressive cytokine involved in liver regeneration, inflammation and fibrosis [16], is also abundant within the liver immune microenvironment and through its complex signalling and pleiotropic functional role exerts a tolerogenic effect [17].

HSCs heavily secrete TGF- $\beta$, which yields profibrogenic and anti-proliferative properties [18]. Activated HSCs contribute to liver tolerogenesis by inhibiting lymphocyte infiltration, inducing PD-L1 expression and facilitate recruitment [19] and functional differentiation of T-regs when naïve CD4+ cells are recruited to professional DCs [20]. HSCs can also prevent the activation CD8+ Tcells through a CD54-mediated mechanism by reducing IL2/IL-2R T-cell signalling [21] and facilitate the generation of myeloid derived suppressor cells (MDSC) [22] suggesting their prominence as immune-regulatory cells despite the fairly limited capacity of functioning as APCs [23].

Alongside LSECs and HSCs, KCs contribute to the liver immune microenvironment as non-migratory liver resident macrophages sitting at the sinusoidal interface with a high phenotypic plasticity in response to danger signals [24]. $\mathrm{KCs}$ respond to damage via expression of a vast repertoire of toll-like receptors, scavenger receptors as well as complement and Fc-gamma receptors [25]. In homoeostatic conditions, KC-mediated antigen presentation promotes tolerogenic immunity by attenuation of $\mathrm{CD} 4+\mathrm{T}$-cell responses, and T-reg expansion [26]. In response to LPS, $\mathrm{KCs}$ polarise the liver sinusoidal microenvironment towards immune-suppression by IL- 6 downregulation and IL-10 release [27]. Mechanistic evidence produced to date suggests tolerance to be a key trait in liver immune homoeostasis (Fig. 1) [28].

\section{Immune-mediated mechanisms in the pathogenesis and progression of HCC}

\section{T-cells}

It has been long time recognised that increased $\mathrm{T}$ lymphocyte infiltrate is associated with improved overall and progression free survival in HCC [29]. However, despite T-cell infiltration tumours ultimately progress and metastasise as a result of the 'exhaustion' of proinflammatory T-cell populations and accumulation of regulatory T-lymphocytes [30-32]. Cytotoxic CD8+ T-cells (CTLs) are a critical component of anti-tumour immunity in HCC and harbinger of favourable prognosis [33]. CTLs initiate T-cell receptor (TCR)-mediated, antigen-dependent cytotoxicity against tumours, being capable of directly inducing cell death via membrane-bound FAS-ligand and inhibit tumour proliferation via IFN- $\gamma$ secretion [7]. CD4+ 


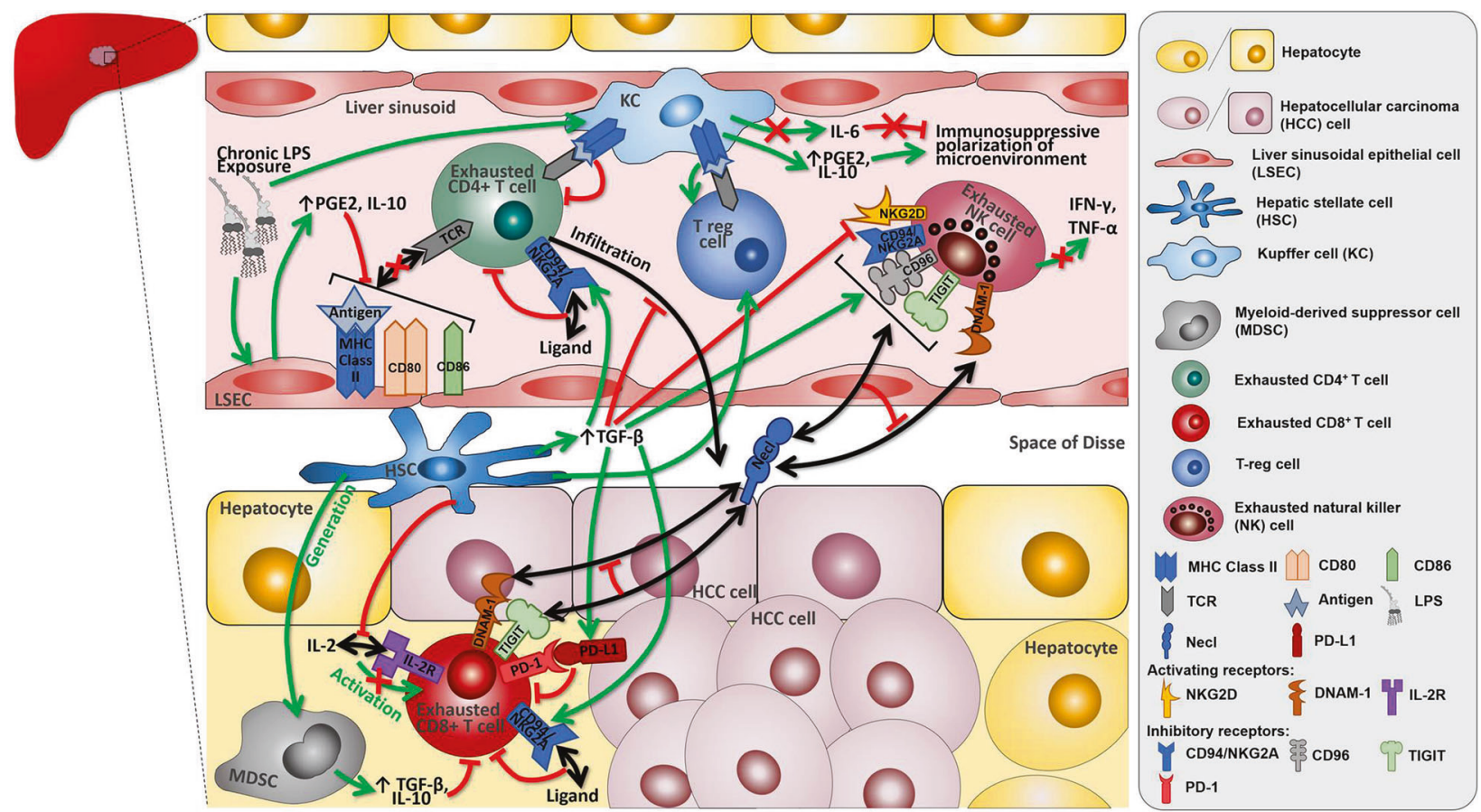

Fig. 1 The complex and multi-faceted functional interactions guiding cancer immune tolerogenesis in hepatocellular carcinoma. Cellular and functional heterogeneity of the HCC tumour microenvironment.

T-helper cells are an integral part of anti-tumour immunity: when activated in the presence of dendritic cell derived type-1 interferon and IL-12, they produce a number of proinflammatory (' $\mathrm{TH}_{1}$ ') cytokines, which promote CTL proliferation and thus anti-tumour immunity [34]. Overexpression of $\mathrm{TH}_{1}$ cytokines (IFN- $\gamma, \mathrm{IL}-2, \mathrm{IL}-1 \alpha$, IL- $1 \beta$ ) is associated with favourable prognosis [35].

T-cell exhaustion is characterised by impaired proinflammatory responses upon stimulation, reduced cytokine production, impaired proliferation and reduced cytotoxicity. Such phenotype is hallmarked by over-expression of co-inhibitory receptors including CTLA-4, PD-1, LAG-3 and TIM-3. Evidence of intra-tumoural and circulating of exhausted CD8+ T-cells is documented as a poor prognostic trait in $\mathrm{HCC}[36,37]$.

Exhaustion within the TME is multifactorial and dominated by a cytokine milieu rich in IL-10 and TGF- $\beta$ that prohibits activation of CTLs and $\mathrm{TH}_{1} \mathrm{CD} 4+\mathrm{T}$-cells $[38,39]$. Single cell analysis of TCR sequences has recently confirmed clonal expansion of exhausted CD8+ Tcell clusters in HCC, indicating that CTL clones expand within the tumour after infiltration and become exhausted [40]. Novel transcriptional regulators of T-cell exhaustion are being increasingly appreciated including TOX, a transcription factor heavily overexpressed in CD8+ TILs that suppresses effector and memory function [41].

The PD-1/PD-L1 pathway is a key actionable driver of immune-exhaustion in HCC, and works by suppression of T-cell receptor signalling via the PI3K/AKT pathway, ultimately inhibiting T-cell survival and growth [42, 43]. High expression of PD-1 [36] and PD-L1 is generally associated with poor prognosis in HCC [44-46] where PD-1 over-expressing TILs can restore their effector function following PD-1 blockade [47]. Alongside PD-1/PD-L1, a growing number of inhibitory pathways has been identified to target anti-tumour CTL function.

CTLA-4 is a well described inhibitory receptor, which is upregulated after T-cell activation and is thought to act by competitively antagonising CD80 and CD86 co-stimulatory molecules and by downstream inhibition of AKT [48].

TIM-3 is expressed on CD4+, CD8+ TILs and intratumoural T-regs in HCC, co-localising with its ligand Galectin-9 expressed on APCs. TIM-3 expression leads to reduced CTL capacity [49-51] and higher circulating TIM3 concentration is associated with HCC susceptibility in $\mathrm{HBV}$-carriers [52].

Other drivers of T-cell exhaustion in HCC include LAG3 , associated to hypofunctional $\mathrm{CD} 8+$ responses in $\mathrm{HCC}$ TILs, which can be reversed upon LAG-3 blockade [53] and B and T-lymphocyte attenuator (BTLA), seen in $>50 \%$ of PD-1+ TILs in HCC and denoting particularly pronounced hypo-functionality [54] and T-cell exclusion [55].

\section{Regulatory T-lymphocytes}

Regulatory T-cells (T-reg) are CD4+/CD25+/FOXP3 + immune-suppressive T-cells whose accumulation in HCC is associated with disease progression [56] and reduced 
survival [31, 57]. They are recruited intratumorally via CCL17/CCL22 secretion by tumour associated macrophages (TAMs) [58, 59]. In addition, T-reg differentiation is promoted by the production of TGF- $\beta$, IL-10 and other mediators including COX-2 and indoleamine 2,3-dioxygenase by stromal and tumour cells [60].

T-regs impair antigen presentation by down-regulating DC expression of CD80 and CD86 [61]. They can directly hamper the cytotoxic capacity of CTLs through the production of suppressive cytokines including TGF- $\beta$ and IL-10 and by competing for and antagonising the effect of IL-2. T-regs can also directly lyse antigen presenting cells via granzyme-mediated cytolysis and crucially express high amounts of the inhibitory signalling molecules mentioned above [62]. Circulating T-regs correlate negatively with survival in HCC [63].

Other suppressive lymphocyte populations have been characterised in the HCC TME.

$\mathrm{TH}_{2} \mathrm{CD} 4+\mathrm{T}$-helper cells, generated when activation occurs in the presence of IL-10 derived from intra-tumoural myeloid cells, exert CTL-inhibitory functions [64]. IL-10 is also produced by another regulatory $\mathrm{T}$-cell population, Tr1 cells. These are induced in HCC by interaction with plasmacytoid dendritic cells via ligation of ICOS [65]. Increased expression of $\mathrm{TH}_{2}$ cytokines (IL-4, IL-5 and IL$10)$ is associated with disease progression and metastasis in HCC [35] as a likely consequence of IL-4-mediated recruitment of TAM, which in turn secrete TGF- $\beta$ and vascular endothelial growth factor (VEGF) [35]. IL-17 producing $\mathrm{TH}_{17}$ subsets have also been reported in HCC. $\mathrm{TH}_{17}$ intratumoural density leads to poor survival through the fostering of angiogenesis [66].

Circulating $\mathrm{TH}_{17}$ cells in $\mathrm{HCC}$ can suppress autologous anti-tumour CTL responses when co-cultured in vitro [67] and are increased in more advanced disease [68].

\section{NK cells}

NK cells are innate lymphoid cells that constitute $\sim 30 \%$ of liver resident lymphocytes - in sharp contrast with the lower frequency of peripheral blood NK cells (range 5-15\%) [69]. NK cells represent a homogeneous population identified by the abundance of specific cell surface receptors (CD56, CD16). Liver resident NK cells (lrNK) are mostly CD56 ${ }^{\text {bright }} \mathrm{CD} 16^{\text {dim }}$ that reside in the thin-walled sinusoids along Kupffer cells, NKT and T-cells in a CCR5 and CXCR6 dependent manner [70, 71]. NK cell tolerance in steady-state liver is ensured by the presence of inhibitory receptors for self MHC-I molecules, mainly killer cell immunoglobulin-like receptors (KIR) and CD94/NKG2A [72]. Conventional circulating $\mathrm{NK}$ cells (CD56 $^{\mathrm{dim}}$ CD16 ${ }^{\text {bright }}$ ) are being recruited to the inflamed liver and, along lrNK cells, are activated by cytokines such as IL-2,
IL-12, IL-18, IL-15 secreted by hepatocytes and Kupffer cells [73]. Upon activation, NK cells operate rapidly, without the requirement for antigen presentation, by producing cytokines (mainly IFN- $\gamma, \mathrm{TNF}-\alpha$ ), chemokines and triggering target cell apoptosis via death-inducing molecules - the FAS receptor and the TNF-Related Apoptosis Inducing Ligand (TRAIL) — and via the release of cytotoxic granules [74].

NK cell activation relies on germ-line encoded stimulatory receptors triggered by self-ligands, viral antigens or stress-induced ligands, rapidly induced in virus infected cells and tumour cells [75]. The C-type lectin-like receptor Natural killer group 2, member D (NKG2D) is a potent antitumour mediator expressed on NK cells, CD8 + T-cells, $\gamma \delta$ T-cells and invariant NKT cells [76]. Human NKG2D binds to highly polymorphic ligands called MHC class-I chainrelated protein $\mathrm{A}$ and $\mathrm{B}$, unique long 16 (UL-16)-binding proteins. High level of NKG2D receptor and/or NKG2D ligands have been reported in chronic liver diseases associated with metabolic disorders [77], HCV/HBV infection [78, 79] and in HCC [80, 81].

Other stimulatory receptors include the natural cytotoxic receptors (NCR) NKp46, NKp30 and NKp44; the FcyRIII (CD16) that mediates antibody-dependent cell cytotoxicity against IgG-coated target cells, and co-stimulatory molecule such as the DNAX accessory molecule-1 (DNAM-1) triggered by adhesion molecules of the Nectin/Nectin-like (Necl) family (Fig. 2). Interestingly, Necl also interact with two inhibitory receptors CD96 on NK cells and the T-cell immunoglobulin and ITIM domain (TIGIT) on NK and CD8+ T-cells, which simultaneously prevents DNAM-1 co-stimulation, leading to reduced NK functionality [82]. Most Necl are overexpressed in HCC where high level of Nectin-4 associates with poor prognosis [83].

Dysfunctional NK cells have been described in settings of chronic inflammation such as NASH [84], viral hepatitis [85] and in the TME [86]. Reduced membrane expression of certain NKG2D ligands in $\mathrm{HCC}$ patients correlate with disease progression and early recurrence $[87,88]$. TGF- $\beta$ induces a suppressive environment in downregulating NKG2D receptors and upregulating inhibitory receptors such as TIGIT and CD96 on NK cells [89, 90] and CD94/ NKG2A on NK and T-cells [91]. In HCC patients, intratumoral NK cells with high level of CD96 were functionally exhausted with reduced production of IFN- $\gamma$ and TNF $\alpha$ and associated with reduced shorter disease-free survival and overall survival times [90].

\section{Myeloid cells}

The two main myeloid cell populations within the TME are TAMs and MDSCs. MDSCs are a more immature myeloid population found in both the peripheral circulation and 
Fig. 2 Principal functional networks driving NK cell function in hepatocellular carcinoma. Key stimulatory and inhibitory interactions involved in NK cell/tumour cell recognition and killing.

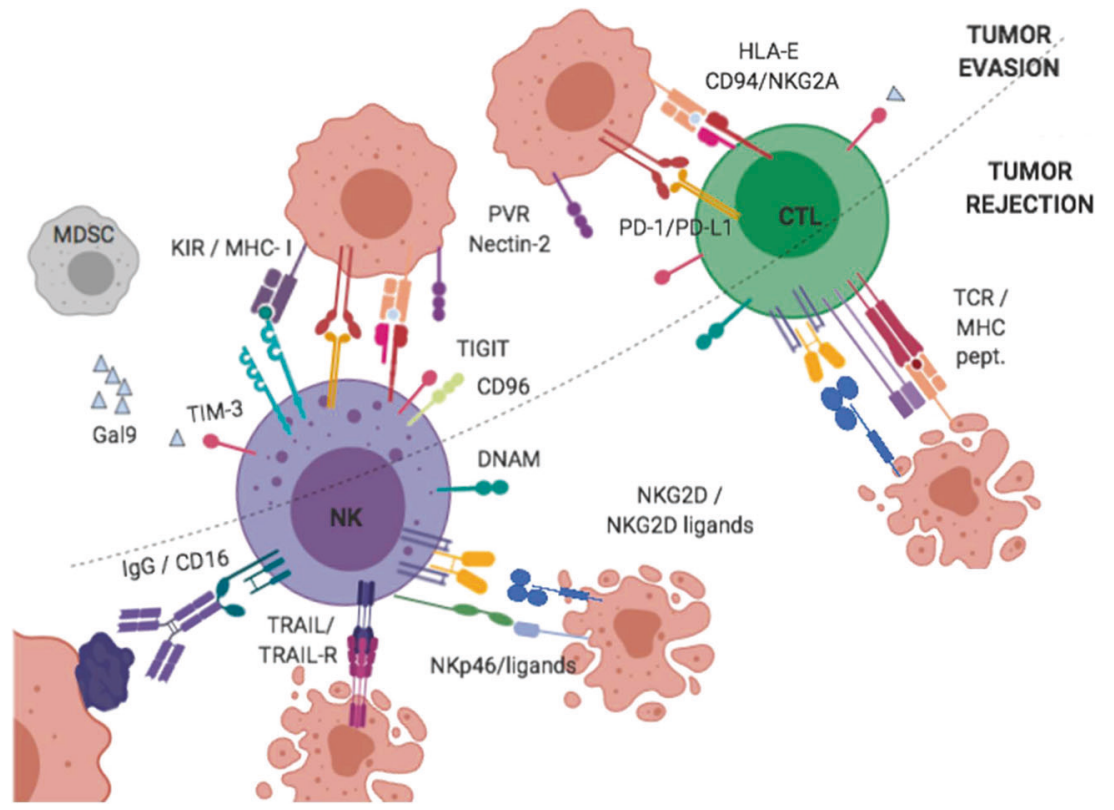

within tumours, whereas TAMs are tissue-resident only. Endothelial and HSC production of CXCL12 promotes intra-tumoural myeloid cell recruitment via chemokine receptor CXCR4 [92]. Infiltrating MDSCs foster tumour progression [93] and higher circulating MDSCs increase the risk of HCC recurrence after ablative therapy [94]. MDSCs deplete arginine in the TME through the production of arginase, resulting in suppression of T-cell proliferation. In addition, they promote T-reg expansion through the production of IL-10 and TGF- $\beta$ and promote inhibitory signalling in effector $\mathrm{T}$ cells through surface expression of PDL1 [95].

TAMs are the predominant tumour-infiltrating leucocyte population and their presence confers poor prognosis in HCC [96]. High IL-10 secretion by MDSCs results in the skewing of resident macrophages and infiltrating monocytes to an immune-regulatory phenotype. They release growth factors including TGF- $\beta$ and VEGF to promote tumour growth and development, promote cancer cell stemness through activation of NF- $\mathrm{KB}$ and metastasis through the production of matrix metalloproteinases [97]. TAMs can also directly inhibit anti-tumour cytotoxic T-cell proliferation and promote regulatory $\mathrm{CD} 4+\mathrm{T}$-cell expansion via surface expression of PD-L1, secretion of IL-10 and TGF- $\beta$ and through the production of nitric oxide and arginase in the same manner as MDSCs.

\section{Immune checkpoint inhibition in HCC}

The systemic treatment of patients with HCC has traditionally been challenged by the intrinsic chemoresistance [98] and concomitant liver dysfunction, a competing risk factor for treatment-related toxicity and mortality [99]. The mainstay of treatment for patients who are not candidates for liver transplantation, resection or loco-regional therapies is multi-targeted molecular therapy with sorafenib [100] or lenvatinib [101], with regorafenib being an approved second-line treatment option in sorafenib-progressors [102]. Whilst effective in improving survival, these therapies are largely cytostatic and therapeutic resistance is a significant limitation to long-term survivorship.

Targeted blockade of CTLA-4 and PD-1/PD-L1 as forerunner molecular targets of cancer-related immune exhaustion has rapidly extended to HCC based on the promising results of ICPI therapy in multiple indications (Table 1, Fig. 3).

\section{CTLA-4 monotherapy}

Therapeutic targeting of CTLA-4 has resulted in the first demonstrable evidence of anti-tumour regression following selective modulation of a T-cell co-inhibitory pathway in melanoma [103]. Whilst characterised by low frequency of anti-tumour responses, single-agent anti-CTLA-4 therapy leads to long-term survivorship in $\sim 20 \%$ of patients, providing evidence of long-lasting immune reconstitution [104].

Tremelimumab, a fully human anti-CTLA-4 IgG2 monoclonal antibody was the first immune checkpoint blocker to be tested in advanced HCC in a 21-patient cohort of advanced, HCV-associated HCC patients. Response rates were modest $(17 \%)$, mirrored by a median time to progression (TTP) of 6.5 months [105]. Whilst lacking longterm survival data, the reported median overall survival (OS) was 8.2 months with a $43 \%$ probability of survival at 1 


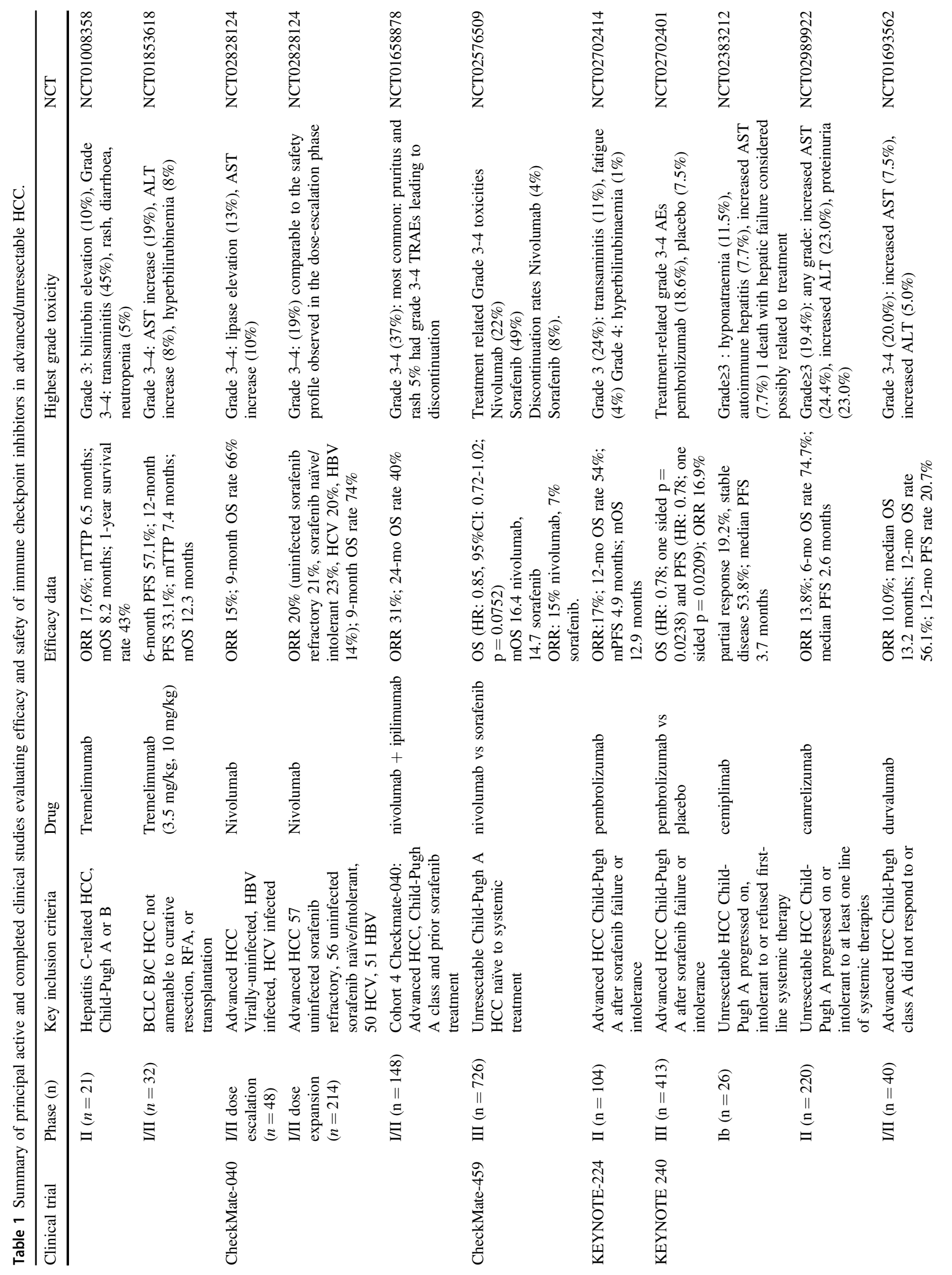




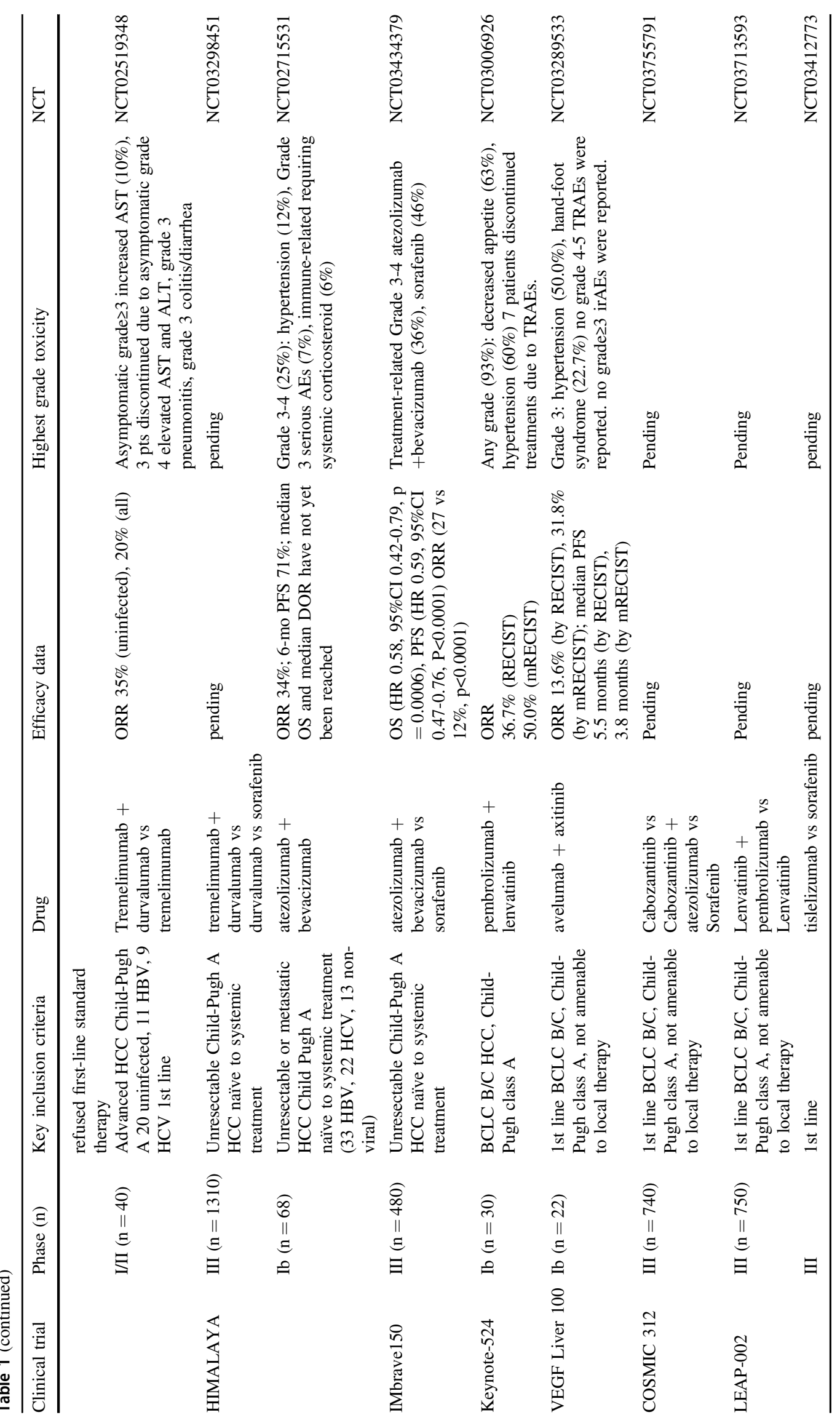




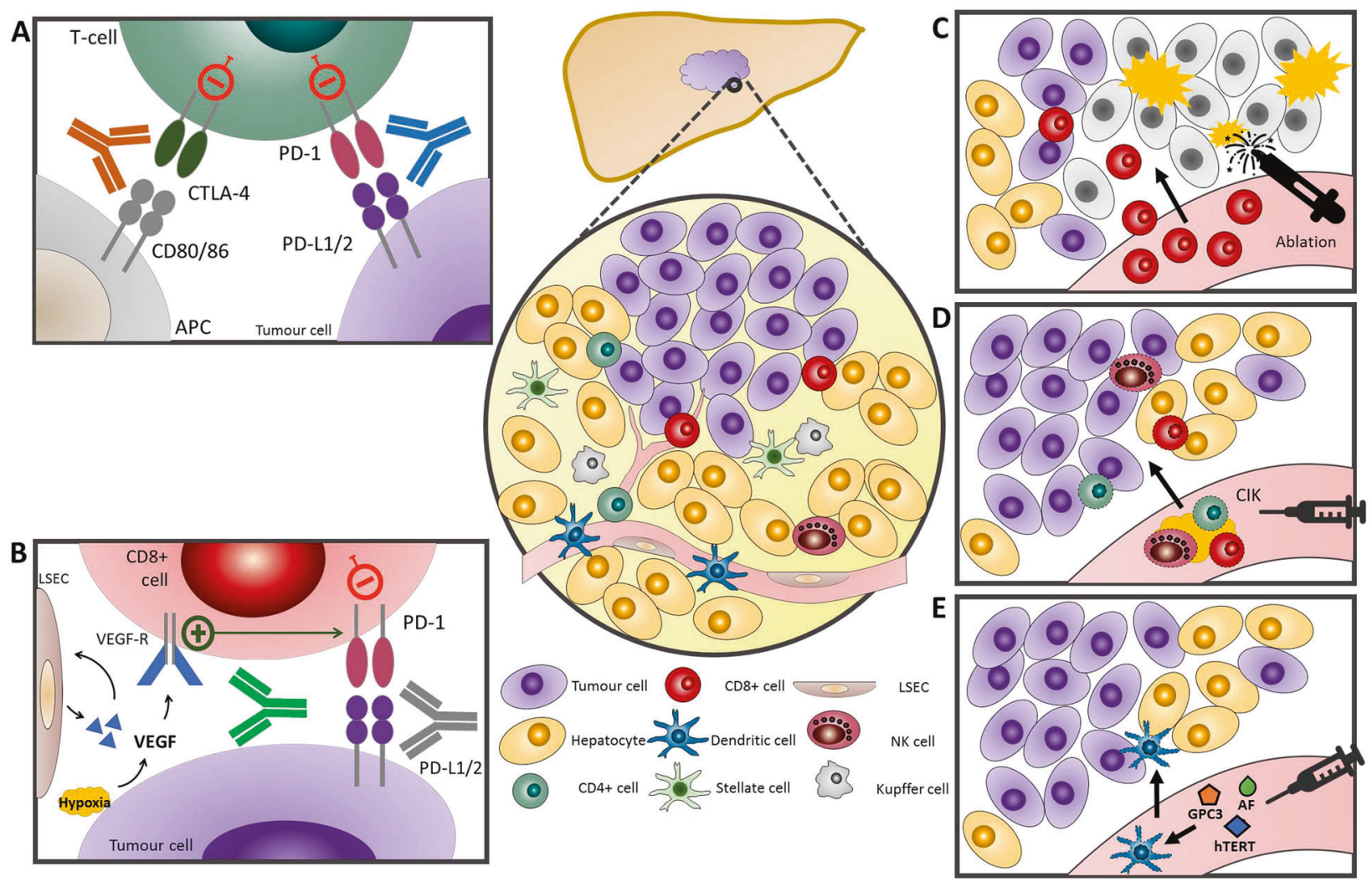

Fig. 3 General overview of immune-based therapies for HCC. a Simultaneous inhibition of CTLA- 4 and the PD- 1 axis by monoclonal antibodies (brown and blue respectively). The effect of dual checkpoint blockade on T-cell immune reconstitution is demonstrated, with CTLA-4 acting mainly on T-reg cells and antigen-presenting cells, and PD-1 acting on effector CD8 + CTLs. b Schematic representation of synergy between anti-angiogenic therapy (green antibody) and PD-1/ PD-L1-targeted therapy. c Locoregional therapies, such as ablation and trans-arterial chemoembolisation are loco-regional inducers of

year. In another open-label single-arm study, Duffy et al. tested tremelimumab at 3.5 and $10 \mathrm{mg} / \mathrm{kg}$ scheduled as six 4-weekly induction infusions followed by 3-monthly maintenance. During induction, at day 36, patients underwent sub-total tumour ablation with the intent to provoke synergistic immunogenic cell death. Five out of 19 evaluable patients achieved a partial response, translating into a TTP of 7.4 months and OS of 12.3 months [106]. Both studies demonstrated evidence of anti-viral activity with falling HCV RNA load and expansion of HCV-specific Tcell responses [105]. Incidence and severity of treatmentrelated adverse events (TRAE) were consistent with the known mechanism of action of anti-CTLA-4 blockade in other indications. Transaminitis $\geq$ Grade 2 occurred in up to $45 \%$ of patients across studies being mostly transient and not associated with overt liver functional decompensation [105]. No unexpected or dose-limiting toxicities (DLTs) were documented. Unlike melanoma, anti-CTLA-4 monotherapy has not undergone extensive testing in the context of large phase III studies leaving open questions around its immunogenic cell death and drive CD8+ cell infiltration into the tumour microenvironment, providing a rationale for combined antiPD-1 therapy. $\mathbf{d}$ Autologous T cell transfer involves ex vivo activation of mixed $\mathrm{T}$ cell/NK cell populations by cytokines (i.e., CIK cells) and reinfusion into the patient with the intent of bypassing immuneevasion and eliciting an anti-tumour responses. e Anti-tumour vaccines against immunodominant peptides of oncofoetal proteins, such as AFP, GPC3 and hTERT, have been combined with ex vivo activation of dendritic cells to promote effective antigen presentation.

efficacy across diverse etiologies of chronic liver disease and its ability to induce long-lasting anti-tumour control.

\section{PD-1/PD-L1 monotherapy}

The clinical efficacy of PD-1/PD-L1 immune checkpoint blockade resides in its ability to augment the effector function of tumour-specific CD8+ T-cells [107], resulting in tumour rejection. The favourable therapeutic index of PD-1/PD-L1 inhibitors and reproducible efficacy has broadened opportunities for therapy in patients with previously untreatable malignancies (for instance B-RAF Wild Type melanoma) or ineligible to traditional therapies (i.e., cisplatin-ineligible urothelial cancer). In HCC, concerns over concomitant liver dysfunction and hepatotropic viral infection led to the need for confirmatory studies verifying the safety of PD-1/PD-L1 blockade in this challenging patient population.

CheckMate-040 is the landmark, multi-cohort, open label, phase I/II study that has assessed the fully human 
anti-PD-1 IgG4 antibody nivolumab in advanced HCC patients for safety and efficacy. The phase I component of the study assessed escalating doses of nivolumab in three concurrent cohorts of patients with virus-uninfected, HBV, $\mathrm{HCV}$-infected advanced $\mathrm{HCC}$ starting from $0.1 \mathrm{mg} \mathrm{mg} / \mathrm{kg}$ and utilising a standard $3+3$ design [8]. Adequate antiviral control was mandated in patients with $\mathrm{HBV}$ infection. The trial completed dose escalation to $10 \mathrm{mg} / \mathrm{kg}$ every 2 weeks with no DLTs and no hepatitis flares. TRAEs were dose-unrelated and included grade 3-4 events in 25\% of patients (12/48). Nivolumab was further tested at $3 \mathrm{mg} / \mathrm{kg}$ in 214 subjects with $\mathrm{HCV}(n=50), \mathrm{HBV}$ infection $(n=51)$ and without viral hepatitis, further stratified in sorafenibnaïve/intolerant $(n=56)$ and sorafenib-progressors $(n=$ 57). Objective response rates (ORRs) were 15 and $20 \%$ across dose-escalation and expansion cohorts and the median OS was 15 months (95\% CI 9.6-20.2) in the doseescalation group. The follow-on phase III study CheckMate-459 failed to show superiority of nivolumab over sorafenib in improving OS as a first-line therapy for unresectable $\mathrm{HCC}(\mathrm{HR}=0.85$, 95\% CI: 0.72-1.02; $p=$ 0.0752) [108].

The humanised anti-PD-1 monoclonal antibody pembrolizumab has been evaluated for safety and efficacy in Keynote-224, a non-randomised phase II study of 104 patients with advanced HCC who had previously discontinued sorafenib due to progressive disease $(80 \%)$ or intolerance $(20 \%)$. None of the $26 \mathrm{HCV}$-positive $(25 \%)$ or 22 HBV-positive patients (21\%) experienced worsening or re-activation of hepatitis. TRAEs of grade 3-4 intensity were seen in 26 patients $(25 \%)$, the most frequent being transaminitis in $6(6 \%)$. The encouraging efficacy of pembrolizumab is demonstrated by the ORR achieved in 18 patients (17\%), $77 \%$ of whom remained in response for over 9 months. Median PFS and OS were 4.9 months (95\% CI 3.4-7.2) and 12.9 months (95\% CI 9.7-15.5) and 1-year OS rate was 54\% (95\% CI 44-63) [9]. Keynote-240 evaluated pembrolizumab in pre-treated patients with advanced HCC in a phase III, randomised, placebo-controlled design. In total, 413 patients with Child-Pugh A, PS 0-1 advanced HCC intolerant or progressors to sorafenib were randomised $2: 1$ to pembrolizumab $(n=278)$ or placebo $(n=135)$, receiving treatment for up to 35 cycles or earlier interruption due to progression or unacceptable toxicity. Keynote240 confirmed the ORR observed in other single-agent PD1 studies (16.9\%) with a median duration of response of 13.8 months (95\% CI 12.7-23.6). Despite an improvement in the two co-primary endpoints of OS (HR $=0.78,95 \% \mathrm{CI}$ : $0.61-0.99 ; p=0.0238)$ and PFS $(\mathrm{HR}=0.78,95 \% \mathrm{CI}$ : $0.61-0.99 ; p=0.0209$ ), the study failed to meet the prespecified threshold for statistical significance [109]. Amongst the reasons considered for the discrepancy between predicted and observed effects of pembrolizumab in this patient population is the rapidly changing landscape of systemic treatment in HCC, with the advent of novel therapies such as regorafenib and cabozantinib having changed the expected survival probability of patients with advanced HCC [110].

Other PD-1 inhibitors with less mature clinical data in HCC include tislelizumab (BGB-A317) [111], camrelizumab (SHR-1210) [112] and cemiplimab (REGN2810) [113]. Data around their safety and preliminary efficacy are available mostly from dose-expansion cohorts of earlyphase clinical studies and confirm incidence and intensity of treatment-related AEs that are in keeping with the mechanism of action of the compounds. The experience with camrelizumab, tested in an open-label study of 220 patients from 13 institutions in China is perhaps the most mature, with evidence of ORR of $13.8 \%$ a median PFS of 2.6 months (95\%CI 2.0-3.3) and 6-months OS rate of $74.7 \%$. In a much smaller 26-patient cohort, cemiplimab resulted in 5 PRs and 14 SDs. Tislelizumab was launched into late-phase development with RATIONALE 301 study after identification of the recommended phase 2 dose and is currently the first study to explore non-inferiority against sorafenib in a randomised controlled phase III study in advanced HCC [114].

Clinical data on anti-PD-L1 monotherapy have been presented as part of a phase I/II study evaluating the IgG1 monoclonal antibody durvalumab in an expansion cohort of 40 HCC patients with Child-Pugh Class A, 93\% of whom sorafenib experienced. The study has reported an ORR of $10 \%$, a median OS of 13.2 months and a 56\% 1-year survival rate, accompanied by a safety profile characterised by a 20\% incidence of G3-4 irAEs, most commonly transaminitis in up to $7 \%$ of patients [115].

\section{Combination therapies}

The evolving clinical experience in the use of PD-1/PD-L1 inhibitors has led to the expansion of combinations aimed at improving ORR and leading to greater survival benefit versus monotherapy. Mechanisms of synergy include simultaneous targeting of multiple co-inhibitory receptors, promotion of immunogenic cell death with local treatments or radiotherapy and re-programming of the TME with targeted anti-cancer agents. The majority of these strategies have been tested in the context of small, single-arm studies in HCC, often in absence of pre-clinical models to guide efficacy testing.

\section{Dual immune checkpoint blockade}

Convincing clinical evidence of synergy from CTLA-4/PD1 co-inhibition in melanoma [116], kidney cancer [117] and NSCLC [118] has led to the understanding that concurrent 
targeting of multiple immune checkpoints leads to an increased magnitude and depth of anti-tumour immune responses across malignancies. The rationale behind dual CTLA-4/PD-1 blockade is evident from the differential and non-redundant immune-biologic role of the two pathways within the cancer immunity cycle, where CTLA-4 is a prominent driver of immune-suppression in tumour-antigen presenting cells and T-regs, whereas PD-1/PD-L1 predominantly downregulates the effectiveness of the CD8 + CTL response.

Clinically, the safety and early efficacy of three different dosing schedules of ipilimumab and nivolumab were tested in cohort 4 of the Checkmate-040 study. Advanced HCC patients with Child-Pugh A class and prior sorafenib treatment were randomised to three arms: nivolumab $1 \mathrm{mg} / \mathrm{kg}+$ ipilimumab $3 \mathrm{mg} / \mathrm{kg}$ or nivolumab $3 \mathrm{mg} / \mathrm{kg}+$ ipilimumab $1 \mathrm{mg} / \mathrm{kg}$ every 3 weeks for four doses followed by nivolumab maintenance ( $240 \mathrm{mg}$ flat dose every 2 weeks) until disease progression or unacceptable toxicity. A third arm evaluated nivolumab $3 \mathrm{mg} / \mathrm{kg}+$ ipilimumab $1 \mathrm{mg} / \mathrm{kg}$ every 6 weeks until discontinuation due to progression or toxicity. Overall, incidence of treatment-related AEs was 37\%, most common being skin toxicity. The discontinuation rate for toxicity was low at 5\%. Analysis of efficacy revealed the combination to yield a $31 \%$ ORR, which compares favourably with the previous experience of nivolumab monotherapy within the same study (14\%) [119].

Durvalumab and tremelimumab have been tested in combination at the dose of $20 \mathrm{mg} / \mathrm{kg}$ and $1 \mathrm{mg} / \mathrm{kg}$ respectively every 4 weeks followed by $20 \mathrm{mg} / \mathrm{kg}$ durvalumab maintenance in a phase I/II study of 40 patients with advanced HCC. In this study $70 \%$ of the patients had received prior systemic treatment and $50 \%$ were hepatitisuninfected. The proportion of severe treatment-related AEs was $20 \%$ and discontinuation rate was $7 \%$. The ORR was $15 \%$, with the entirety of confirmed responses seen in uninfected patients. Disease-control rates at 16 weeks from study commencement was 57\% [120]. The encouraging results from this study have led to the inception of the HIMALAYA study, a randomised, multi-centre phase III study that will compare durvalumab and tremelimumab against durvalumab monotherapy or sorafenib as first-line therapy for HCC.

\section{NK cell-based therapies}

To enhance NK cell activity, blockade of the inhibitory KIR receptors using the anti-KIR antibody Lirilumab (IPH2102/ BMS-986015) is being evaluated in combination with nivolumab or nivolumab and ipilimumab in advanced solid tumours including HCC (NCT01714739). Safety profile of Lirilumab in monotherapy or combination showed no
DLTs, with the exception of increased infusion-related reactions [121, 122].

Other inhibitory receptors shared by NK cells and T-cells including TIGIT, LAG-3, TIM-3, BTLA and NKG2A have been identified as novel checkpoint blockade [123] holding promise in combination therapy with anti-PD-1/PD-L1 or anti-CTLA-4 antibodies [88]. NKG2A blockade in animal model of $\mathrm{HCV}$ infection led to enhanced NK and CD8 $+\mathrm{T}$ cell functions promoting $\mathrm{HCV}$ clearance [124]. NKG2A blockade combined with anti-PD-1/PD-L1 blockade was recently shown to enhance $\mathrm{NK}$ and T-cell anti-tumour response [125, 126] in murine lymphoma tumour models and in human in vitro experiments [125]. Preliminary results of a phase II trial combining monalizumab, a humanised anti-NKG2A antibody, and cetuximab, an antiEGFR in head and neck squamous cell carcinoma patients showed a $31 \%$ objective response rate (NCT02643550). These results will likely encourage trials in other types of cancer including HCC where HLA-E ligands for NKG2A have been evidenced [125]. Successful clinical translation of these therapies to HCC requires a better understanding of the regulation and function of these pathways.

\section{Targeted therapies}

Molecularly targeted therapies have played a pivotal role in the medical management of HCC, with sorafenib having solidly remained the first and for nearly a decade the only drug therapy to demonstrate a significant OS benefit in treatment-naïve Child-Pugh A HCC patients [100]. Pursuing combination therapy with ICPI and molecularly targeted agents is not only justified by evidence of single-agent activity but also by the complex bidirectional relationship existing between angiogenesis and immunity [127]. Resistance to anti-angiogenic therapy is in fact at least in part determined by an immune-suppressive microenvironment characterised by higher T-reg infiltration and stronger PDL1 expression [128]. The expression of PD-L1 itself is strongly placed under the transcriptional regulation of hypoxia inducible factor 1-alpha [129]. In HCC, sorafenib therapy induces tumoural PD-L1 overexpression [130], and pre-clinical evidence in mouse models suggests this to correlate with T-reg accumulation and M2-macrophage polarisation through hypoxia, drawing a translationally appealing rationale for combination therapy [131]. Inhibition of tumour angiogenesis, and in particular VEGF aids normalisation of the endothelial barrier by regulating key adhesion molecules for immune cell homing to the tumour. VEGF also inhibits DC maturation and accentuates PD-1 expression of tumour-infiltrating CD8 + T-cells highlighting the potential for synergy between VEGF inhibition and ICPI therapy [132]. 
An increasing number of studies of PD-1/PD-L1 inhibitors and anti-angiogenics is underway. On the basis of the positive safety and efficacy data from GO30140 [133], the combination of atezolizumab $(1200 \mathrm{mg})$ co-administered 3weekly with bevacizumab $(15 \mathrm{mg} / \mathrm{kg})(\mathrm{A}+\mathrm{B})$ was the first to reach efficacy in the phase III Imbrave 150 study ( $n=$ 501 ), the first to show superiority of combination immunotherapy in improving OS (HR $0.58,95 \%$ CI $0.42-0.79, p$ $=0.0006)$, PFS (HR 0.59, 95\% CI 0.47-0.76, $P<0.0001)$ and ORR ( 27 vs $12 \%, p<0.0001)$ versus sorafenib. The favourable safety profile, with mainly asymptomatic toxicities (proteinuria/hypertension) comes as a great challenge to standard of care and is likely to change the treatment landscape of HCC [134].

Keynote-524, an open-label, phase Ib study of pembrolizumab and lenvatinib in patients with unresectable HCC echoed these results demonstrating promising antitumour activity and acceptable safety, although with higher rates of symptomatic toxicities. After a safety lead-in of 6 patients and an expansion of 24 patients previously untreated for HCC, at median follow up of 9.7 months ORR by RECIST criteria were $36.7 \%$ increasing to $50 \%$ when modified RECIST (mRECIST) criteria were used. On the basis of the promising initial results the protocol was amended to allow for the recruitment of 100 patients to study part 2 and led to breakthrough FDA approval of the combination on the basis of ORR [135].

The phase Ib VEGF Liver 100 study (NCT03289533) of the PD-L1 IgG1 antibody avelumab co-administered at the dose of $10 \mathrm{mg} / \mathrm{kg}$ every 2 weeks with the VEGF receptor kinase 1, 2, 3 inhibitor axitinib has demonstrated an ORR of $13.6 \%$ based on RECIST 1.1 and $31.8 \%$ when evaluated by mRECIST criteria. Median PFS was 5.5 and 3.8 months based on RECIST and mRECIST respectively. Despite fairly high levels of grade 3 TKI-related toxicities including hypertension (50\%) and hand-foot syndrome (22.7\%), no grade $\geq 3$ irAEs and no treatment related were reported [136].

\section{Loco-regional therapies}

Loco-regional therapies including ablation and trans-arterial chemoembolization (TACE) have traditionally played a major role in the treatment of liver-confined HCC. Mounting evidence suggests loco-regional therapies to produce quantifiable changes in immune cell subsets, leading to the premise that the local ischaemic and cytotoxic effect provoked by thermal, radio-frequency ablation or chemoembolization of liver tumours might promote immunogenic cell death [137]. The pilot study of tremelimumab combined with ablation/chemoembolisation is to date the most comprehensive prospective study that has looked at the synergistic effect between local and systemic therapy [106]. In a subset of patients who experienced clinical benefit, evidence of increased $\mathrm{CD} 8+$ infiltrate in tumour biopsies collected post treatment gives a positive although preliminary confirmation of the immunogenic activity of the combination. The lack of a comparator arm makes it impossible to disentangle the superadded effect of CTLA-4 inhibition from that of local therapy. Equally, the heterogeneity of ablative techniques used makes the clinical outcomes difficult to generalise to the broader population of patients with liver-confined HCC. A number of studies are actively recruiting in the intermediate-stage HCC space, with nivolumab, pembrolizumab being tested in combination with conventional (NCT03397654, NCT0314370), DEB-TACE and yttrium-90 radioembolization. Preliminary results of the PETAL clinical trial of pembrolizumab administered 3-weekly after conventional TACE has shown no evidence of synergistic toxicity with TACE [138]. Efficacy results of these early-phase clinical studies are eagerly awaited given the failure of anti-angiogenic therapy to promote clinically-significant improvements in long-term anti-tumour control and survival in this patient population [139].

\section{Other immunotherapeutic approaches}

Beyond ICPIs, a number of other immunotherapeutic approaches have been studied over the years in primary liver cancer. The existence of measurable, naturally occurring responses against TAA in peripheral blood of patients with HCC has prompted the investigation of anti-tumour vaccine studies against immunodominant peptides of oncofoetal proteins such as alpha-fetoprotein (AFP), glypican-3 (GPC3), telomerase reverse transcriptase and many others such as MAGE-A1, NY-ESO-1 [140].

A key barrier to the effective development of vaccines as therapies for HCC stands in the co-existence of multiple inhibitory mechanisms including enrichment of infiltrating T-regs [140]. Whilst strategies including pre-conditioning with low-dose cyclophosphamide (a T-reg depleting agent) or stimulation with colony stimulating factors have been attempted [141], these have been unsuccessful in producing long-term, clinically meaningful anti-tumour responses. Ex vivo stimulation of DCs aims to correct a key primary mechanism of cancer immune evasion by promoting effective antigen presentation and induce immunological memory [142]. Results of DC-based vaccinations have however been mixed in the clinic. Whilst capable of generating measurable anti-TAA responses [143], clinical efficacy is limited to disease stabilisation with lowfrequency proportion of partial responses in most studies [143-145]. Heterogeneity in DC vaccination manufacturing and the need for dedicated facilities for apheresis and re- 
infusion of DCs makes this approach difficult to adopt in absence of more convincing evidence of efficacy [146].

Adoptive cell transfer consists of the re-infusion of autologous $\mathrm{T}$ cells following in vitro activation with exogenously supplemented cytokines. Infusion of autologous $\mathrm{T}$ cells for 6 months following in vitro stimulation with CD3 and IL-2 has been evaluated in a randomised controlled study of 76 patients. After a median follow-up period of 4.4 years, adoptive T-cell immunotherapy decreased recurrence probability by $18 \%$ [147]. Beneficial effects from adoptive re-infusion of activated cytokine induced killer cells, a mixed population of $\mathrm{CD} 3+/ \mathrm{CD} 56+$ and CD3+/CD56- T-cells and CD3-/CD56+ natural killer cells, were confirmed in studies enroling patients who achieved complete response following resection, ablation or percutaneous ethanol injection [148]. Combined infusion of $\mathrm{T}$ cells and DCs has also been attempted, leading to improvement in post-operative survival [149]. The positive results from adoptive cellular immunotherapy and the evidence of TAA-specific responses in HCC have stimulated research into chimeric antigen receptor T-cells, which combine antigen-specificity with the potential to infuse a fully active cytotoxic effector T-cell population. Whilst initial pre-clinical evidence is promising $[150,151]$ concerns over toxicity warrants a careful clinical development in patients with HCC [152].

\section{Predictive biomarkers}

The probability of achieving clinical benefit from ICPI therapy is restricted to a fraction of patients with HCC. High-throughput studies on tissue samples have identified $25 \%$ of patients to harbour transcriptomic hallmarks of a pro-inflammatory response associated with features of adaptive or exhausted immunity [153]. There is an acute need to translate this knowledge into clinically available predictive correlates of response and survival to spare patients from potentially ineffective therapies characterised by the risk of life-threatening immunotoxicity.

\section{PD-L1 expression}

Immunohistochemical detection of PD-L1 has emerged a putative predictor of response to PD-1/PD-L1-targeted checkpoint inhibitors with variable predictive ability across malignancies. Assessment of PD-L1 expression is challenged by clonal diversity of the antibodies used for detection, varying methodology for scoring of tumour and infiltrating cells and biologic heterogeneity of the sampled tissue. In HCC evidence for a predictive role for PD-L1 staining has been elusive. In Keynote-224, evaluation of PD-L1 expression by 22c3 PharmDx companion diagnostic assay was restricted to fresh or archival tissue from 52 of 104 participants. Combined tumoural and stromal PD-L1 expression was associated with higher ORR $(p=0.021)$ and PFS $(p=0.026)$ to pembrolizumab, whereas tumour cell staining alone was not ( $p=0.088$ and 0.096 , respectively) [9]. In Checkmate 040, PD-L1 expression in tumour cells was evaluated using the $28-8$ PharmDx assay. In the expansion cohort $(n=174), 9 / 34$ patients with PD-L1 $>1 \%$ achieved an objective response (26\%) compared with 26 out of 140 (19\%) with PD-L1<1\% [8]. Analytical heterogeneity across PD-L1 assays is substantial [154], a factor that might contribute to the poor performance of this biomarker.

\section{Tumour mutational burden (TMB)}

Tumour mutational burden (TMB) measures the number of somatic non-synonymous mutations per mega-base (Mut/ $\mathrm{Mb}$ ) in the coding genome of tumour cell [155]. It is believed that TMB-high tumours, mostly defined as those harbouring $>10$ mut/Mb, are enriched in tumour neoantigens and therefore intrinsically immunogenic. TMB is an emerging predictor of response across malignancies. However, compared with other tumours, HCC has median number of $5 \mathrm{Mut} / \mathrm{Mb}$ [156-159], ranging from 0.5 to $10 \mathrm{Mut} / \mathrm{Mb}$ [156, 157]. Impairment of mismatch repair mechanisms, which contribute to a hypermutated phenotype is also infrequent in HCC [160]. Analyses of genomic databases including a small fraction of ICPI recipients $(n=$ 17) confirmed the low prevalence of TMB-high HCC (median $4 \mathrm{Mut} / \mathrm{Mb}$ ) and limited evidence for a predictive role of TMB, highlighting the need for more comprehensive evaluation of genomic and non-genomic predictors of outcome [161].

\section{The gut microbiota as a source of biomarkers}

Microbial proteins are able to prime $\mathrm{T}$-cell responses [162] and play a fundamental role in the induction, training and function of the host immune system [163, 164]. The gut microbiome determines resistance to ICPI in a number of tumours treated with PD-1 blockade [165-167]. The liver does not harbour a known intrinsic microbiome but the gut microbiota plays a critical role in liver inflammation, chronic fibrosis, liver cirrhosis and HCC development via the gut-liver axis [168-170]. A pilot study of $8 \mathrm{HCC}$ patients treated with PD-1 inhibitors has revealed taxonomic diversity and enrichment in 20 species including Akkermansia and Ruminococcaceae to predict for response [171] suggesting characteristic alterations in the gut microbiota profile to have potential as predictive biomarkers of clinical benefit in ICPIrecipients. The precise molecular mechanisms that may 
facilitate anti-tumour immunity warrant further elucidation in larger cohorts.

\section{Conclusions and future directions}

With its robust immune/inflammatory pathogenesis, HCC remains a strong candidate for the development of immunebased therapies. The rapid expansion of immunotherapy has however been only partially successful. To date, cell-based therapies remain promising but limited in widespread clinical application. ICPIs yield objective anti-tumour responses but their effect in improving survival is still unproven. The plethora of redundant immune-suppressive signals coupled with the lack of robust biomarkers for stratification appear key barriers to an effective deployment of immunotherapy. Rationale selection of immunotherapeutic combinations may yield a window of opportunity to improve outcomes across the various stages of HCC.

Acknowledgements The authors would like to acknowledge the infrastructure support provided by Imperial Experimental Cancer Medicine Centre, Cancer Research UK Imperial Centre. DJP is supported by grant funding from the Wellcome Trust Strategic Fund (PS3416) and Cancer Research UK for the immune phenotyping of HCC (Postdoctoral Bursary Grant Ref. C57701/A26137). SJM is funded by a Wellcome Trust Clinical Research Training Fellowship.

Author contributions Manuscript concept and design: DJP. Acquisition of data: DJP, NG, PF, RM, TM, SKM, MT, CNW, RS, LR. Analysis and interpretation of data: DJP, NG, PF, RM, TM, SKM, MT, CNW, RS, LR. Drafting of the manuscript: DJP. Critical revision of the manuscript for important intellectual content: All the authors. Statistical analysis: N.A. Obtained funding: DJP. Administrative, technical, or material support: DJP. Study supervision: DJP.

\section{Compliance with ethical standards}

Conflict of interest DJP received lecture fees from ViiV Healthcare, Roche, Bayer Healthcare and travel expenses from BMS and Bayer Healthcare; consulting fees for Mina Therapeutics, Roche, EISAI; received research funding (to institution) from MSD, BMS. LR received lectures fees from AstraZeneca, AbbVie, Gilead, Roche; advisory board/consulting role fees from Lilly, Bayer, Sirtex Medical, ArQule, Exelixis, Ipsen, Celgene, Eisai, Hengrui Therapeutics, MSD, Baxter, Amgen, Italfarmaco, Sanofi, Incyte; travel expenses from ArQule and Ipsen.

Publisher's note Springer Nature remains neutral with regard to jurisdictional claims in published maps and institutional affiliations.

Open Access This article is licensed under a Creative Commons Attribution 4.0 International License, which permits use, sharing, adaptation, distribution and reproduction in any medium or format, as long as you give appropriate credit to the original author(s) and the source, provide a link to the Creative Commons license, and indicate if changes were made. The images or other third party material in this article are included in the article's Creative Commons license, unless indicated otherwise in a credit line to the material. If material is not included in the article's Creative Commons license and your intended use is not permitted by statutory regulation or exceeds the permitted use, you will need to obtain permission directly from the copyright holder. To view a copy of this license, visit http://creativecommons. org/licenses/by/4.0/.

\section{References}

1. Kim D, Li AA, Perumpail BJ, Gadiparthi C, Kim W, Cholankeril $\mathrm{G}$, et al. Changing trends in etiology-based and ethnicity-based annual mortality rates of cirrhosis and hepatocellular carcinoma in the United States. Hepatology. 2019;69:1064-74.

2. Bertuccio P, Turati F, Carioli G, Rodriguez T, La Vecchia C, Malvezzi M, et al. Global trends and predictions in hepatocellular carcinoma mortality. J Hepatol. 2017;67:302-9.

3. Pinato DJ, Sharma R, Allara E, Yen C, Arizumi T, Kubota K, et al. The ALBI grade provides objective hepatic reserve estimation across each BCLC stage of hepatocellular carcinoma. J Hepatol. 2017;66:338-46.

4. Yegin EG, Oymaci E, Karatay E, Coker A. Progress in surgical and nonsurgical approaches for hepatocellular carcinoma treatment. Hepatobiliary Pancreat Dis Int. 2016;15:234-56.

5. Mazzaferro V, Sposito C, Zhou J, Pinna AD, De Carlis L, Fan J, et al. Metroticket 2.0 model for analysis of competing risks of death after liver transplantation for hepatocellular carcinoma. Gastroenterology. 2018;154:128-39.

6. Finn RS, Merle P, Granito A, Huang Y-H, Bodoky G, Pracht M, et al. Outcomes of sequential treatment with sorafenib followed by regorafenib for HCC: Additional analyses from the phase III RESORCE trial. J Hepatol. 2018;69:353-8.

7. Mittal D, Gubin MM, Schreiber RD, Smyth MJ. New insights into cancer immunoediting and its three component phaseselimination, equilibrium and escape. Curr Opin Immunol. 2014:27:16-25.

8. El-Khoueiry AB, Sangro B, Yau T, Crocenzi TS, Kudo M, Hsu $\mathrm{C}$, et al. Nivolumab in patients with advanced hepatocellular carcinoma (CheckMate 040): an open-label, non-comparative, phase $1 / 2$ dose escalation and expansion trial. Lancet. 2017;389:2492-502.

9. Zhu AX, Finn RS, Edeline J, Cattan S, Ogasawara S, Palmer D, et al. Pembrolizumab in patients with advanced hepatocellular carcinoma previously treated with sorafenib (KEYNOTE-224): a non-randomised, open-label phase 2 trial. Lancet Oncol. 2018;19:940-52.

10. Flynn MJ, Sayed AA, Sharma R, Siddique A, Pinato DJ. Challenges and opportunities in the clinical development of immune checkpoint inhibitors for hepatocellular carcinoma. Hepatology. 2019;69:2258-70.

11. Guillot A, Tacke F. Liver macrophages: old dogmas and new insights. Hepatol Commun. 2019;3:730-43.

12. Mehrfeld C, Zenner S, Kornek M, Lukacs-Kornek V. The contribution of non-professional antigen-presenting cells to immunity and tolerance in the liver. Front Immunol. 2018;9:635.

13. Knolle P, Uhrig A, Hegenbarth S, Löser E, Schmitt E, Gerken G, et al. IL-10 down-regulates $\mathrm{T}$ cell activation by antigenpresenting liver sinusoidal endothelial cells through decreased antigen uptake via the mannose receptor and lowered surface expression of accessory molecules. Clin Exp Immunol. 1998;114:427.

14. Shetty S, Lalor PF, Adams DH. Liver sinusoidal endothelial cells - gatekeepers of hepatic immunity. Nat Rev Gastroenterol Hepatol. 2018;15:555-67.

15. Knolle PA, Germann T, Treichel U, Uhrig A, Schmitt E, Hegenbarth $S$, et al. Endotoxin down-regulates $T$ cell activation 
by antigen-presenting liver sinusoidal endothelial cells. J Immunol. 1999;162:1401-7.

16. Bissell DM, Wang S-S, Jarnagin W, Roll FJ. Cell-specific expression of transforming growth factor-beta in rat liver. Evidence for autocrine regulation of hepatocyte proliferation. J Clin Investig. 1995;96:447-55.

17. Fabregat I, Moreno-Càceres J, Sánchez A, Dooley S, Dewidar B, Giannelli G, et al. TGF- $\beta$ signalling and liver disease. FEBS J. 2016;283:2219-32.

18. Karkampouna S, ten Dijke P, Dooley S, Kruithof-de Julio M. TGF $\beta$ signaling in liver regeneration. Curr Pharm Des. 2012;18:4103-13.

19. Zhao W, Zhang L, Yin Z, Su W, Ren G, Zhou C, et al. Activated hepatic stellate cells promote hepatocellular carcinoma development in immunocompetent mice. Int $\mathrm{J}$ Cancer. 2011;129:2651-61.

20. Dunham RM, Thapa M, Velazquez VM, Elrod EJ, Denning TL, Pulendran B, et al. Hepatic stellate cells preferentially induce Foxp3 + regulatory $\mathrm{T}$ cells by production of retinoic acid. $\mathrm{J}$ Immunol. 2013;190:2009-16.

21. Schildberg FA, Wojtalla A, Siegmund SV, Endl E, Diehl L, Abdullah Z, et al. Murine hepatic stellate cells veto CD8 T cell activation by a CD54-dependent mechanism. Hepatology. 2011;54:262-72.

22. Höchst B, Schildberg FA, Sauerborn P, Gäbel YA, Gevensleben $\mathrm{H}$, Goltz D, et al. Activated human hepatic stellate cells induce myeloid derived suppressor cells from peripheral blood monocytes in a CD44-dependent fashion. J Hepatol. 2013;59:528-35.

23. Schildberg FA, Kurts C, Knolle PA. Prominent regulatory but weak antigen-presenting cell function of hepatic stellate cells. Hepatology. 2011;54:1108.

24. Tacke F. Targeting hepatic macrophages to treat liver diseases. J Hepatol. 2017;66:1300-12.

25. Varol C, Mildner A, Jung S. Macrophages: development and tissue specialization. Annu Rev Immunol. 2015;33:643-75.

26. Heymann F, Peusquens J, Ludwig-Portugall I, Kohlhepp M, Ergen C, Niemietz $P$, et al. Liver inflammation abrogates immunological tolerance induced by Kupffer cells. Hepatology. 2015;62:279-91.

27. Knoll P, Schlaak J, Uhrig A, Kempf P, zum Büschenfelde K-HM, Gerken G. Human Kupffer cells secrete IL-10 in response to lipopolysaccharide (LPS) challenge. J Hepatol. 1995;22:226-9.

28. Heymann F, Tacke F. Immunology in the liver-from homeostasis to disease. Nat Rev Gastroenterol Hepatol. 2016;13:88.

29. Ding W, Xu X, Qian Y, Xue W, Wang Y, Du J, et al. Prognostic value of tumor-infiltrating lymphocytes in hepatocellular carcinoma: a meta-analysis. Medicine. 2018;97:e13301.

30. Chiou S-H, Sheu B-C, Chang W-C, Huang S-C, Hong-Nerng H. Current concepts of tumor-infiltrating lymphocytes in human malignancies. J Reprod Immunol. 2005;67:35-50.

31. Gao Q, Qiu S-J, Fan J, Zhou J, Wang X-Y, Xiao Y-S, et al. Intratumoral balance of regulatory and cytotoxic $\mathrm{T}$ cells is associated with prognosis of hepatocellular carcinoma after resection. J Clin Oncol. 2007;25:2586-93.

32. Unitt E, Rushbrook SM, Marshall A, Davies S, Gibbs P, Morris LS, et al. Compromised lymphocytes infiltrate hepatocellular carcinoma: the role of T-regulatory cells. Hepatology. 2005;41:722-30.

33. Wada Y, Nakashima O, Kutami R, Yamamoto O, Kojiro M. Clinicopathological study on hepatocellular carcinoma with lymphocytic infiltration. Hepatology. 1998;27:407-14.

34. Anguille S, Smits EL, Bryant C, Van Acker HH, Goossens H, Lion E, et al. Dendritic cells as pharmacological tools for cancer immunotherapy. Pharmacol Rev. 2015;67:731-53.

35. Budhu A, Forgues M, Ye Q-H, Jia H-L, He P, Zanetti KA, et al. Prediction of venous metastases, recurrence, and prognosis in hepatocellular carcinoma based on a unique immune response signature of the liver microenvironment. Cancer Cell. 2006;10:99-111.

36. Ma J, Zheng B, Goswami S, Meng L, Zhang D, Cao C, et al. $\mathrm{PD} 1(\mathrm{Hi}) \mathrm{CD} 8(+) \mathrm{T}$ cells correlate with exhausted signature and poor clinical outcome in hepatocellular carcinoma. J Immunother Cancer. 2019;7:331.

37. Tauber C, Schultheiss M, Luca R, Buettner N, Llewellyn-Lacey $\mathrm{S}$, Emmerich $\mathrm{F}$, et al. Inefficient induction of circulating TAAspecific CD8+ T-cell responses in hepatocellular carcinoma. Oncotarget. 2019;10:5194-206.

38. Bunt SK, Yang L, Sinha P, Clements VK, Leips J, OstrandRosenberg S. Reduced inflammation in the tumor microenvironment delays the accumulation of myeloid-derived suppressor cells and limits tumor progression. Cancer Res. 2007;67:10019-26.

39. Vignali DA, Collison LW, Workman CJ. How regulatory T cells work. Nat Rev Immunol. 2008;8:523.

40. Zheng C, Zheng L, Yoo J-K, Guo H, Zhang Y, Guo X, et al. Landscape of infiltrating $\mathrm{T}$ cells in liver cancer revealed by single-cell sequencing. Cell. 2017;169:1342-56. e1316

41. Wang X, He Q, Shen H, Xia A, Tian W, Yu W, et al. TOX promotes the exhaustion of antitumor $\mathrm{CD} 8(+) \mathrm{T}$ cells by preventing PD1 degradation in hepatocellular carcinoma. J Hepatol. 2019;71:731-41.

42. Parry RV, Chemnitz JM, Frauwirth KA, Lanfranco AR, Braunstein I, Kobayashi SV, et al. CTLA-4 and PD-1 receptors inhibit T-cell activation by distinct mechanisms. Mol Cell Biol. 2005;25:9543-53.

43. Patsoukis N, Brown J, Petkova V, Liu F, Li L, Boussiotis VA. Selective effects of PD-1 on Akt and Ras pathways regulate molecular components of the cell cycle and inhibit T cell proliferation. Sci Signal. 2012;5:ra46.

44. Chang H, Jung W, Kim A, Kim HK, Kim WB, Kim JH, et al. Expression and prognostic significance of programmed death protein 1 and programmed death ligand-1, and cytotoxic $\mathrm{T}$ lymphocyte-associated molecule-4 in hepatocellular carcinoma. Apmis. 2017;125:690-8.

45. Jung HI, Jeong D, Ji S, Ahn TS, Bae SH, Chin S, et al. Overexpression of PD-L1 and PD-L2 is associated with poor prognosis in patients with hepatocellular carcinoma. Cancer Res Treat: Off J Korean Cancer Assoc. 2017;49:246.

46. Liao H, Chen W, Dai Y, Richardson JJ, Guo J, Yuan K, et al. Expression of programmed cell death-ligands in hepatocellular carcinoma: correlation with immune microenvironment and survival outcomes. Front Oncol. 2019;9:883.

47. Zhou G, Sprengers D, Boor PPC, Doukas M, Schutz H, Mancham $S$, et al. Antibodies against immune checkpoint molecules restore functions of tumor-infiltrating $\mathrm{T}$ cells in hepatocellular carcinomas. Gastroenterology. 2017;153:1107-19. e1110

48. Chambers CA, Kuhns MS, Egen JG, Allison JP. CTLA-4mediated inhibition in regulation of $\mathrm{T}$ cell responses: mechanisms and manipulation in tumor immunotherapy. Annu Rev Immunol. 2001;19:565-94.

49. Anderson AC. Tim-3: an emerging target in the cancer immunotherapy landscape. Cancer Immunol Res. 2014;2:393-8.

50. Sakuishi K, Apetoh L, Sullivan JM, Blazar BR, Kuchroo VK, Anderson AC. Targeting Tim-3 and PD-1 pathways to reverse T cell exhaustion and restore anti-tumor immunity. J Exp Med. 2010;207:2187-94.

51. Yan J, Zhang Y, Zhang JP, Liang J, Li L, Zheng L. Tim-3 expression defines regulatory $\mathrm{T}$ cells in human tumors. PLoS ONE. 2013;8:e58006.

52. Li F, Li N, Sang J, Fan X, Deng H, Zhang X, et al. Highly elevated soluble Tim-3 levels correlate with increased hepatocellular carcinoma risk and poor survival of hepatocellular 
carcinoma patients in chronic hepatitis B virus infection. Cancer Manag Res. 2018;10:941-51.

53. Grosso JF, Kelleher CC, Harris TJ, Maris CH, Hipkiss EL, De Marzo A, et al. LAG-3 regulates CD8 $+\mathrm{T}$ cell accumulation and effector function in murine self-and tumor-tolerance systems. J Clin Investig. 2007;117:3383-92.

54. Zhao Q, Huang ZL, He M, Gao Z, Kuang DM. BTLA identifies dysfunctional PD-1-expressing CD4(+) T cells in human hepatocellular carcinoma. Oncoimmunology. 2016;5:e1254855.

55. Hokuto D, Sho M, Yamato I, Yasuda S, Obara S, Nomi T, et al. Clinical impact of herpesvirus entry mediator expression in human hepatocellular carcinoma. Eur J Cancer. 2015;51:157-65.

56. Chen K-J, Lin S-Z, Zhou L, Xie H-Y, Zhou W-H, Taki-Eldin A, et al. Selective recruitment of regulatory T cell through CCR6CCL20 in hepatocellular carcinoma fosters tumor progression and predicts poor prognosis. PloS ONE. 2011;6:e24671.

57. Langhans B, Nischalke HD, Kramer B, Dold L, Lutz P, Mohr R, et al. Role of regulatory $\mathrm{T}$ cells and checkpoint inhibition in hepatocellular carcinoma. Cancer Immunol Immunother. 2019;68:2055-66.

58. Alissafi T, Hatzioannou A, Legaki A, Varveri A, Verginis P. Balancing cancer immunotherapy and immune-related adverse events: the emerging role of regulatory $\mathrm{T}$ cells. J Autoimmun. 2019;104:102310.

59. Ren L, Yu Y, Wang L, Zhu Z, Lu R, Yao Z. Hypoxia-induced CCL28 promotes recruitment of regulatory $\mathrm{T}$ cells and tumor growth in liver cancer. Oncotarget. 2016;7:75763.

60. Bilate AM, Lafaille JJ. Induced CD4+ Foxp3+ regulatory T cells in immune tolerance. Annu Rev Immunol. 2012;30:733-58.

61. Larmonier N, Marron M, Zeng Y, Cantrell J, Romanoski A, Sepassi M, et al. Tumor-derived CD4+ CD25+ regulatory T cell suppression of dendritic cell function involves TGF- $\beta$ and IL-10. Cancer Immunol, Immunother. 2007;56:48-59.

62. Shevach EM. Mechanisms of foxp3 + T regulatory cell-mediated suppression. Immunity. 2009;30:636-45.

63. An Y, Gao S, Zhao WC, Qiu BA, Xia NX, Zhang PJ, et al. Transforming growth factor-beta and peripheral regulatory cells are negatively correlated with the overall survival of hepatocellular carcinoma. World J Gastroenterol. 2018;24:2733-40.

64. Prieto J, Melero I, Sangro B. Immunological landscape and immunotherapy of hepatocellular carcinoma. Nat Rev Gastroenterol Hepatol. 2015;12:681.

65. Pedroza-Gonzalez A, Zhou G, Vargas-Mendez E, Boor PP, Mancham S, Verhoef C, et al. Tumor-infiltrating plasmacytoid dendritic cells promote immunosuppression by $\operatorname{Tr} 1$ cells in human liver tumors. Oncoimmunology. 2015;4:e1008355.

66. Zhang J-P, Yan J, Xu J, Pang X-H, Chen M-S, Li L, et al. Increased intratumoral IL-17-producing cells correlate with poor survival in hepatocellular carcinoma patients. J Hepatol. 2009;50:980-9.

67. Zhao F, Hoechst B, Gamrekelashvili J, Ormandy LA, Voigtlander T, Wedemeyer H, et al. Human CCR4+ CCR6+ Th17 cells suppress autologous CD8 $+\mathrm{T}$ cell responses. J Immunol. 2012;188:6055-62.

68. Liao Y, Wang B, Huang ZL, Shi M, Yu XJ, Zheng L, et al. Increased circulating Th17 cells after transarterial chemoembolization correlate with improved survival in stage III hepatocellular carcinoma: a prospective study. PLoS ONE. 2013;8:e60444.

69. Norris S, Collins C, Doherty DG, Smith F, McEntee G, Traynor $\mathrm{O}$, et al. Resident human hepatic lymphocytes are phenotypically different from circulating lymphocytes. J Hepatol. 1998;28:84-90.

70. Hudspeth K, Donadon M, Cimino M, Pontarini E, Tentorio P, Preti M, et al. Human liver-resident CD56bright/CD16neg $\mathrm{NK}$ cells are retained within hepatic sinusoids via the engagement of CCR5 and CXCR6 pathways. J Autoimmun. 2016;66:40-50.
71. Stegmann KA, Robertson F, Hansi N, Gill U, Pallant C, Christophides T, et al. CXCR6 marks a novel subset of T-bet lo Eomes hi natural killer cells residing in human liver. Sci Rep. 2016;6:26157.

72. Harmon C, Robinson MW, Fahey R, Whelan S, Houlihan DD, Geoghegan J, et al. Tissue-resident Eomeshi T-betlo CD56bright NK cells with reduced proinflammatory potential are enriched in the adult human liver. Eur J Immunol. 2016;46:2111-20.

73. Kelly AM, Golden-Mason L, Traynor O, Geoghegan J, McEntee G, Hegarty JE, et al. Changes in hepatic immunoregulatory cytokines in patients with metastatic colorectal carcinoma: implications for hepatic anti-tumour immunity. Cytokine. 2006;35:171-9.

74. Shi F-D, Ljunggren H-G, La Cava A, Van Kaer L. Organ-specific features of natural killer cells. Nat Rev Immunol. 2011;11:658.

75. Lanier LL. NK cell recognition. Annu Rev Immunol. 2005;23:225-74.

76. Raulet DH, Guerra N. Oncogenic stress sensed by the immune system: role of natural killer cell receptors. Nat Rev Immunol. 2009;9:568

77. Kahraman A, Schlattjan M, Kocabayoglu P, Yildiz-Meziletoglu S, Schlensak M, Fingas CD, et al. Major histocompatibility complex class I-related chains A and B (MIC A/B): a novel role in nonalcoholic steatohepatitis. Hepatology. 2010;51:92-102.

78. Kennedy P, Gehring A, Nowbath A, Selden C, Quaglia A, Dhillon A, et al. The expression and function of NKG2D molecule on intrahepatic CD8 $+\mathrm{T}$ cells in chronic viral hepatitis. J Viral Hepat. 2008;15:901-9.

79. Oliviero B, Varchetta S, Paudice E, Michelone G, Zaramella M, Mavilio D, et al. Natural killer cell functional dichotomy in chronic hepatitis $\mathrm{B}$ and chronic hepatitis $\mathrm{C}$ virus infections. Gastroenterology. 2009;137:1151-60. e1157

80. Ghadially H, Brown L, Lloyd C, Lewis L, Lewis A, Dillon J, et al. MHC class I chain-related protein A and B (MICA and MICB) are predominantly expressed intracellularly in tumour and normal tissue. Br J Cancer. 2017;116:1208.

81. Jinushi M, Takehara T, Tatsumi T, Kanto T, Groh V, Spies T, et al. Expression and role of MICA and MICB in human hepatocellular carcinomas and their regulation by retinoic acid. Int $\mathrm{J}$ Cancer. 2003;104:354-61.

82. Sanchez-Correa B, Valhondo I, Hassouneh F, Lopez-Sejas N, Pera A, Bergua JM, et al. DNAM-1 and the TIGIT/PVRIG/ TACTILE axis: novel immune checkpoints for natural killer cellbased cancer immunotherapy. Cancers. 2019;11:877.

83. Ma J, Sheng Z, Lv Y, Liu W, Yao Q, Pan T, et al. Expression and clinical significance of Nectin-4 in hepatocellular carcinoma. OncoTargets Ther. 2016;9:183.

84. Michelet X, Dyck L, Hogan A, Loftus RM, Duquette D, Wei K, et al. Metabolic reprogramming of natural killer cells in obesity limits antitumor responses. Nat Immunol. 2018;19:1330.

85. Varchetta S, Mele D, Mantovani S, Oliviero B, Cremonesi E, Ludovisi $\mathrm{S}$, et al. Impaired intrahepatic natural killer cell cytotoxic function in chronic hepatitis $\mathrm{C}$ virus infection. Hepatology. 2012;56:841-9.

86. Sheppard S, Ferry A, Guedes J, Guerra N. The paradoxical role of NKG2D in cancer immunity. Front Immunol. 2018;9:1808

87. Fang L, Gong J, Wang Y, Liu R, Li Z, Wang Z, et al. MICA/B expression is inhibited by unfolded protein response and associated with poor prognosis in human hepatocellular carcinoma. $\mathrm{J}$ Exp Clin Cancer Res. 2014;33:76.

88. Kamimura H, Yamagiwa S, Tsuchiya A, Takamura M, Matsuda Y, Ohkoshi S, et al. Reduced NKG2D ligand expression in hepatocellular carcinoma correlates with early recurrence. J Hepatol. 2012;56:381-8.

89. Harmon C, Jameson G, Almuaili D, Houlihan DD, Hoti E, Geoghegan J, et al. Liver-derived TGF- $\beta$ maintains the Eomeshi 
Tbetlo phenotype of liver resident natural killer cells. Front Immunol. 2019;10:1502.

90. Sun H, Huang Q, Huang M, Wen H, Lin R, Zheng M, et al. Human CD96 correlates to natural killer cell exhaustion and predicts the prognosis of human hepatocellular carcinoma. Hepatology. 2019;70:168-83.

91. Guerra N, Benlhassan K, Carayol G, Guillard M, Pardoux C, Chouaib S, et al. Effect of tumor growth factor-beta on NK receptor expression by allostimulated CD8 + T lymphocytes. Eur Cytokine Netw. 1999;10:357-64.

92. Chen Y, Huang Y, Reiberger T, Duyverman AM, Huang P, Samuel R, et al. Differential effects of sorafenib on liver versus tumor fibrosis mediated by stromal-derived factor 1 alpha/C-X-C receptor type 4 axis and myeloid differentiation antigen-positive myeloid cell infiltration in mice. Hepatology. 2014;59:1435-47.

93. Arihara F, Mizukoshi E, Kitahara M, Takata Y, Arai K, Yamashita T, et al. Increase in CD14+ HLA-DR-/low myeloidderived suppressor cells in hepatocellular carcinoma patients and its impact on prognosis. Cancer Immunol, Immunother. 2013;62:1421-30.

94. Gao XH, Tian L, Wu J, Ma XL, Zhang CY, Zhou Y, et al. Circulating CD14+ HLA-DR-/low myeloid-derived suppressor cells predicted early recurrence of hepatocellular carcinoma after surgery. Hepatol Res. 2017;47:1061-71.

95. Hoechst B, Ormandy LA, Ballmaier M, Lehner F, Krüger C, Manns MP, et al. A new population of myeloid-derived suppressor cells in hepatocellular carcinoma patients induces CD4+ CD25+ Foxp3 + T cells. Gastroenterology. 2008;135:234-43.

96. Kuang D-M, Zhao Q, Peng C, Xu J, Zhang J-P, Wu C, et al. Activated monocytes in peritumoral stroma of hepatocellular carcinoma foster immune privilege and disease progression through PD-L1. J Exp Med. 2009;206:1327-37.

97. Ugel S, De Sanctis F, Mandruzzato S, Bronte V. Tumor-induced myeloid deviation: when myeloid-derived suppressor cells meet tumor-associated macrophages. J Clin Investig. 2015; 125:3365-76.

98. Lohitesh K, Chowdhury R, Mukherjee S. Resistance a major hindrance to chemotherapy in hepatocellular carcinoma: an insight. Cancer Cell Int. 2018;18:44.

99. Thomas M. Molecular targeted therapy for hepatocellular carcinoma. J Gastroenterol. 2009;44:136-41.

100. Llovet JM, Ricci S, Mazzaferro V, Hilgard P, Gane E, Blanc JF, et al. Sorafenib in advanced hepatocellular carcinoma. N Engl J Med. 2008;359:378-90.

101. Kudo M, Finn RS, Qin S, Han KH, Ikeda K, Piscaglia F, et al. Lenvatinib versus sorafenib in first-line treatment of patients with unresectable hepatocellular carcinoma: a randomised phase 3 non-inferiority trial. Lancet. 2018;391:1163-73.

102. Bruix J, Qin S, Merle P, Granito A, Huang YH, Bodoky G, et al. Regorafenib for patients with hepatocellular carcinoma who progressed on sorafenib treatment (RESORCE): a randomised, double-blind, placebo-controlled, phase 3 trial. Lancet. 2017;389:56-66.

103. Hodi FS, O’Day SJ, McDermott DF, Weber RW, Sosman JA, Haanen JB, et al. Improved survival with ipilimumab in patients with metastatic melanoma. N Engl J Med. 2010;363:711-23.

104. Schadendorf D, Hodi FS, Robert C, Weber JS, Margolin K, Hamid $\mathrm{O}$, et al. Pooled analysis of long-term survival data from phase II and phase III trials of ipilimumab in unresectable or metastatic melanoma. J Clin Oncol. 2015;33:1889.

105. Sangro B, Gomez-Martin C, de la Mata M, Iñarrairaegui M, Garralda E, Barrera P, et al. A clinical trial of CTLA-4 blockade with tremelimumab in patients with hepatocellular carcinoma and chronic hepatitis C. J Hepatol. 2013;59:81-88.

106. Duffy AG, Ulahannan SV, Makorova-Rusher O, Rahma O, Wedemeyer H, Pratt D, et al. Tremelimumab in combination with ablation in patients with advanced hepatocellular carcinoma. J Hepatol. 2017;66:545-51.

107. Ahn E, Araki K, Hashimoto M, Li W, Riley JL, Cheung J, et al. Role of PD-1 during effector CD8 T cell differentiation. Proc Natl Acad Sci USA. 2018;115:4749-54.

108. Yau T, Park JW, Finn RS, Cheng A-L, Mathurin P, Edeline J. et al. LBA38_PRCheckMate 459: a randomized, multi-center phase III study of nivolumab (NIVO) vs sorafenib (SOR) as firstline (1L) treatment in patients (pts) with advanced hepatocellular carcinoma (aHCC). Ann Oncol. 2019;30(suppl_5):v851-934.

109. Finn RS, Ryoo BY, Merle P, Kudo M, Bouattour M, Lim HY, et al. Pembrolizumab as second-line therapy in patients with advanced hepatocellular carcinoma in KEYNOTE-240: a randomized, double-blind, phase III trial. J Clin Oncol. 2020;38:193-202.

110. Kudo M, Trevisani F, Abou-Alfa GK, Rimassa L. Hepatocellular carcinoma: therapeutic guidelines and medical treatment. Liver Cancer. 2017;6:16-26.

111. Yen C-J, Markman B, Chao Y, Hill A, Kang J, Wang L. et al. P140 Preliminary results of a phase 1A/1B study of BGB-A317, an anti-PD-1 monoclonal antibody (mAb), in patients with advanced hepatocellular carcinoma (HCC). Ann Oncol. 2017;28 (suppl_3):iii54.

112. Qin SK, Ren ZG, Meng ZQ, Chen ZD, Chai XL, Xiong JP. et al. LBA27A randomized multicentered phase II study to evaluate SHR-1210 (PD-1 antibody) in subjects with advanced hepatocellular carcinoma (HCC) who failed or intolerable to prior systemic treatment. Ann Oncol. 2018;29(suppl_8): viii719-20.

113. Pishvaian MJ, Weiss GJ, Falchook GS, Yee N, Gil-Martin M, Shahda S. et al. 1151PCemiplimab, a human monoclonal antiPD-1, in patients (pts) with advanced or metastatic hepatocellular carcinoma (HCC): Data from an expansion cohort in a phase I study. Ann Oncol. 2018;29(suppl_8):viii400.

114. Qin S, Finn RS, Kudo M, Meyer T, Vogel A, Ducreux M, et al. RATIONALE 301 study: tislelizumab versus sorafenib as firstline treatment for unresectable hepatocellular carcinoma. Future Oncol. 2019;15:1811-22.

115. Wainberg ZA, Segal NH, Jaeger D, Lee K-H, Marshall J, Antonia SJ, et al. Safety and clinical activity of durvalumab monotherapy in patients with hepatocellular carcinoma (HCC). J Clin Oncol. 2017;35:4071.

116. Larkin J, Chiarion-Sileni V, Gonzalez R, Grob JJ, Cowey CL, Lao $\mathrm{CD}$, et al. Combined nivolumab and ipilimumab or monotherapy in untreated melanoma. N Engl J Med. 2015;373:23-34.

117. Hammers HJ, Plimack ER, Infante JR, Rini BI, McDermott DF, Lewis LD, et al. Safety and efficacy of nivolumab in combination with ipilimumab in metastatic renal cell carcinoma: the CheckMate 016 study. J Clin Oncol. 2017;35:3851-8.

118. Hellmann MD, Ciuleanu T-E, Pluzanski A, Lee JS, Otterson GA, Audigier-Valette $\mathrm{C}$, et al. Nivolumab plus ipilimumab in lung cancer with a high tumor mutational burden. N Engl J Med. 2018;378:2093-104.

119. Yau T, Kang Y-K, Kim T-Y, El-Khoueiry AB, Santoro A, Sangro B. et al. Nivolumab (NIVO)+ ipilimumab (IPI) combination therapy in patients (pts) with advanced hepatocellular carcinoma (aHCC): results from CheckMate 040. J Clin Oncol. 2019;37(suppl_15):4012.

120. Kelley RK, Abou-Alfa GK, Bendell JC, Kim T-Y, Borad MJ, Yong W-P. et al. Phase I/II study of durvalumab and tremelimumab in patients with unresectable hepatocellular carcinoma (HCC): Phase I safety and efficacy analyses. J Clin Oncol. 2019;35(suppl_15):4072.

121. George B, Kelly K, Ko A, Soliman H, Trunova N, Wainberg Z. et al. Phase I study of nivolumab (nivo) + nab-paclitaxel (nab-P) in solid tumors: results from the pancreatic cancer (PC) and non- 
small cell lung cancer (NSCLC) cohorts. Ann Oncol. 2016;11 (suppl_10):S211-2.

122. Vey N, Karlin L, Sadot-Lebouvier S, Broussais F, BertonRigaud D, Rey J, et al. A phase 1 study of lirilumab (antibody against killer immunoglobulin-like receptor antibody KIR2D; IPH2102) in patients with solid tumors and hematologic malignancies. Oncotarget. 2018;9:17675.

123. Dougall WC, Kurtulus S, Smyth MJ, Anderson AC. TIGIT and CD 96: new checkpoint receptor targets for cancer immunotherapy. Immunol Rev. 2017;276:112-20.

124. Zhang C, Wang X-m, Li S-r, Twelkmeyer T, Wang W-h, Zhang $\mathrm{S}-\mathrm{y}$, et al. NKG2A is a NK cell exhaustion checkpoint for HCV persistence. Nat Commun. 2019;10:1507.

125. André P, Denis C, Soulas C, Bourbon-Caillet C, Lopez J, Arnoux T, et al. Anti-NKG2A mAb is a checkpoint inhibitor that promotes anti-tumor immunity by unleashing both $\mathrm{T}$ and NK cells. Cell. 2018;175:1731-43. e1713

126. van Montfoort N, Borst L, Korrer MJ, Sluijter M, Marijt KA, Santegoets SJ, et al. NKG2A blockade potentiates CD8 T cell immunity induced by cancer vaccines. Cell. 2018;175:1744-55. e1715

127. Schaaf MB, Garg AD, Agostinis P. Defining the role of the tumor vasculature in antitumor immunity and immunotherapy. Cell Death Dis. 2018;9:115.

128. Liu X-D, Hoang A, Zhou L, Kalra S, Yetil A, Sun M, et al. Resistance to antiangiogenic therapy is associated with an immunosuppressive tumor microenvironment in metastatic renal cell carcinoma. Cancer Immunol Res. 2015;3:1017-29.

129. Chen J, Jiang C, Jin L, Zhang X. Regulation of PD-L1: a novel role of pro-survival signalling in cancer. Ann Oncol. 2015; 27:409-16.

130. Lu L-C, Lee Y-H, Chang C-J, Shun C-T, Fang C-Y, Shao Y-Y, et al. Increased expression of programmed death-ligand 1 in infiltrating immune cells in hepatocellular carcinoma tissues after Sorafenib treatment. Liver Cancer. 2019;8:110-20.

131. Chen Y, Ramjiawan RR, Reiberger T, Ng MR, Hato T, Huang $\mathrm{Y}$, et al. CXCR4 inhibition in tumor microenvironment facilitates anti-programmed death receptor-1 immunotherapy in sorafenibtreated hepatocellular carcinoma in mice. Hepatology. 2015; 61:1591-602.

132. Ramjiawan RR, Griffioen AW, Duda DG. Anti-angiogenesis for cancer revisited: Is there a role for combinations with immunotherapy? Angiogenesis. 2017;20:185-204.

133. Pishvaian MJ, Lee MS, Ryoo B-Y, Stein S, Lee K-H, Verret W. et al. LBA26 Updated safety and clinical activity results from a phase Ib study of atezolizumab + bevacizumab in hepatocellular carcinoma (HCC). Ann Oncol. 2018;29(suppl_8):viii718-9.

134. Cheng A-L, Qin S, Ikeda M, Galle P, Ducreux M, Zhu A. et al. LBA3I Mbrave150: Efficacy and safety results from a ph III study evaluating atezolizumab (atezo) + bevacizumab (bev) vs sorafenib (Sor) as first treatment (tx) for patients (pts) with unresectable hepatocellular carcinoma (HCC). Ann Oncol. 2019;30(suppl_9):ix183-202.

135. Llovet JM, Kudo M, Cheng A-L, Finn RS, Galle PR, Kaneko S. et al. Lenvatinib (len) plus pembrolizumab (pembro) for the firstline treatment of patients (pts) with advanced hepatocellular carcinoma (HCC): Phase 3 LEAP-002 study. J Clin Oncol. 2019;37:TPS4152.

136. Kudo M, Motomura K, Wada Y, Inaba Y, Sakamoto Y, Kurosaki M. et al. First-line avelumab + axitinib in patients with advanced hepatocellular carcinoma: Results from a phase $1 \mathrm{~b}$ trial (VEGF Liver 100). J Clin Oncol. 2019;37(suppl_15):4072

137. Greten TF, Mauda-Havakuk M, Heinrich B, Korangy F, Wood BJ. Combined locoregional-immunotherapy for liver cancer. J Hepatol. 2019;70:999-1007.
138. Pinato DJ, Cole T, Bengsh B, Tait P, Sayed AA, Abomeli F. et al. A phase Ib study of pembrolizumab following trans-arterial chemoembolization (TACE) in hepatocellular carcinoma (HCC): PETAL. ESMO. 2019;30(suppl_5):v288.

139. Meyer T, Fox R, Ma YT, Ross PJ, James MW, Sturgess R, et al. Sorafenib in combination with transarterial chemoembolisation in patients with unresectable hepatocellular carcinoma (TACE 2): a randomised placebo-controlled, double-blind, phase 3 trial. Lancet Gastroenterol Hepatol. 2017;2:565-75.

140. Schmidt N, Flecken T, Thimme R. Tumor-associated antigen specific $\mathrm{CD} 8+\mathrm{T}$ cells in hepatocellular carcinoma-a promising target for immunotherapy. Oncoimmunology. 2014;3: e954919.

141. Greten TF, Forner A, Korangy F, N'Kontchou G, Barget N, Ayuso C, et al. A phase II open label trial evaluating safety and efficacy of a telomerase peptide vaccination in patients with advanced hepatocellular carcinoma. BMC Cancer. 2010;10:209.

142. Sabado RL, Balan S, Bhardwaj N. Dendritic cell-based immunotherapy. Cell Res. 2017;27:74.

143. Palmer DH, Midgley RS, Mirza N, Torr EE, Ahmed F, Steele JC, et al. A phase II study of adoptive immunotherapy using dendritic cells pulsed with tumor lysate in patients with hepatocellular carcinoma. Hepatology. 2009;49:124-32.

144. Butterfield LH, Ribas A, Dissette VB, Lee Y, Yang JQ, De la Rocha $\mathrm{P}$, et al. A phase I/II trial testing immunization of hepatocellular carcinoma patients with dendritic cells pulsed with four $\alpha$-fetoprotein peptides. Clin Cancer Res. 2006;12:2817-25.

145. Lee W-C, Wang H-C, Hung C-F, Huang P-F, Lia C-R, Chen MF. Vaccination of advanced hepatocellular carcinoma patients with tumor lysate-pulsed dendritic cells: a clinical trial. J Immunother. 2005;28:496-504.

146. Zhou Y, Bosch ML, Salgaller ML. Current methods for loading dendritic cells with tumor antigen for the induction of antitumor immunity. J Immunother. 2002;25:289-303.

147. Takayama T, Sekine T, Makuuchi M, Yamasaki S, Kosuge T, Yamamoto J, et al. Adoptive immunotherapy to lower postsurgical recurrence rates of hepatocellular carcinoma: a randomised trial. Lancet. 2000;356:802-7.

148. Lee JH, Lee J-H, Lim Y-S, Yeon JE, Song T-J, Yu SJ, et al Adjuvant immunotherapy with autologous cytokine-induced killer cells for hepatocellular carcinoma. Gastroenterology. 2015;148:1383-91. e1386

149. Shimizu K, Kotera Y, Aruga A, Takeshita N, Katagiri S, Ariizumi $\mathrm{S}-\mathrm{i}$, et al. Postoperative dendritic cell vaccine plus activated T-cell transfer improves the survival of patients with invasive hepatocellular carcinoma. Hum Vaccines Immunother. 2014;10:970-6.

150. Jiang Z, Jiang X, Chen S, Lai Y, Wei X, Li B, et al. Anti-GPC3CAR $T$ cells suppress the growth of tumor cells in patientderived xenografts of hepatocellular carcinoma. Front Immunol. 2017;7:690.

151. Pan Z, Di S, Shi B, Jiang H, Shi Z, Liu Y, et al. Increased antitumor activities of glypican-3-specific chimeric antigen receptor-modified T cells by coexpression of a soluble PD1-CH3 fusion protein. Cancer Immunol, Immunother. 2018;67:1621-34.

152. Mizukoshi E, Kaneko S. Immune cell therapy for hepatocellular carcinoma. J Hematol Oncol. 2019;12:52.

153. Sia D, Jiao Y, Martinez-Quetglas I, Kuchuk O, Villacorta-Martin $\mathrm{C}$, de Moura MC, et al. Identification of an immune-specific class of hepatocellular carcinoma, based on molecular features. Gastroenterology. 2017;153:812-26.

154. Pinato DJ, Mauri FA, Spina P, Cain O, Siddique A, Goldin R, et al. Clinical implications of heterogeneity in PD-L1 immunohistochemical detection in hepatocellular carcinoma: the Blueprint-HCC study. Br J Cancer. 2019;120:1033. 
155. Büttner R, Longshore JW, López-Ríos F, Merkelbach-Bruse S, Normanno N, Rouleau E, et al. Implementing TMB measurement in clinical practice: considerations on assay requirements. ESMO Open. 2019;4:e000442.

156. Alexandrov LB, Nik-Zainal S, Wedge DC, Aparicio SA, Behjati $\mathrm{S}$, Biankin $\mathrm{AV}$, et al. Signatures of mutational processes in human cancer. Nature. 2013;500:415.

157. Totoki Y, Tatsuno K, Covington KR, Ueda H, Creighton CJ, Kato $\mathrm{M}$, et al. Trans-ancestry mutational landscape of hepatocellular carcinoma genomes. Nat Genet. 2014;46:1267.

158. Yarchoan M, Hopkins A, Jaffee EM. Tumor mutational burden and response rate to PD-1 inhibition. N. Engl J Med. 2017; 377:2500-1.

159. Zucman-Rossi J, Villanueva A, Nault J-C, Llovet JM. Genetic landscape and biomarkers of hepatocellular carcinoma. Gastroenterology. 2015;149:1226-39. e1224

160. Yamamoto H, Itoh F, Fukushima H, Kaneto H, Sasaki S, Ohmura T, et al. Infrequent widespread microsatellite instability in hepatocellular carcinomas. Int J Oncol. 2000;16:543-50.

161. Ang C, Klempner SJ, Ali SM, Madison R, Ross JS, Severson EA, et al. Prevalence of established and emerging biomarkers of immune checkpoint inhibitor response in advanced hepatocellular carcinoma. Oncotarget. 2019;10:4018.

162. Shen H, Miller JF, Fan X, Kolwyck D, Ahmed R, Harty JT. Compartmentalization of bacterial antigens: differential effects on priming of $\mathrm{CD} 8 \mathrm{~T}$ cells and protective immunity. Cell. 1998;92:535-45.

163. Belkaid Y, Hand TW. Role of the microbiota in immunity and inflammation. Cell. 2014;157:121-41.
164. Tray N, Weber JS, Adams S. Predictive biomarkers for checkpoint immunotherapy: current status and challenges for clinical application. Cancer Immunol Res. 2018;6:1122-8.

165. Gopalakrishnan V, Spencer C, Nezi L, Reuben A, Andrews M, Karpinets $\mathrm{T}$, et al. Gut microbiome modulates response to anti-PD-1 immunotherapy in melanoma patients. Science. 2018;359:97-103.

166. Matson V, Fessler J, Bao R, Chongsuwat T, Zha Y, Alegre M$\mathrm{L}$, et al. The commensal microbiome is associated with anti-PD-1 efficacy in metastatic melanoma patients. Science. 2018;359:104-8.

167. Routy B, Le Chatelier E, Derosa L, Duong CP, Alou MT, Daillère R, et al. Gut microbiome influences efficacy of PD1-based immunotherapy against epithelial tumors. Science. 2018;359:91-97.

168. Dapito DH, Mencin A, Gwak G-Y, Pradere J-P, Jang M-K, Mederacke I, et al. Promotion of hepatocellular carcinoma by the intestinal microbiota and TLR4. Cancer Cell. 2012;21:504-16.

169. Jiang J-W, Chen X-H, Ren Z-G, Zheng S-S. Gut microbial dysbiosis associates hepatocellular carcinoma via the gut-liver axis. Hepatobiliary Pancreat Dis Int. 2018;18:19-27.

170. Yoshimoto S, Loo TM, Atarashi K, Kanda H, Sato S, Oyadomari S, et al. Obesity-induced gut microbial metabolite promotes liver cancer through senescence secretome. Nature. 2013;499:97.

171. Zheng Y, Wang T, Tu X, Huang Y, Zhang H, Tan D, et al. Gut microbiome affects the response to anti-PD-1 immunotherapy in patients with hepatocellular carcinoma. J Immunother Cancer. 2019;7:193. 